ELUA

ISSN 2171-6692

Núm. 35, 2021, págs. 125-162

https://doi.org/10.14198/ELUA2021.35.7

\title{
LA EXPRESIÓN DEL TABÚ EN EL HABLA DE MÁLAGA
}

\section{THE EXPRESSION OF TABOO IN THE SPEECH OF MÁLAGA}

\author{
Gloria Guerrero Ramos \\ Universidad de Málaga, España \\ gguerrero@uma.es \\ https://orcid.org/0000-0001-8188-4570 \\ Manuel Fernando Pérez Lagos \\ Universidad de Málaga, España \\ mfperez@uma.es \\ https://orcid.org/0000-0003-3292-0218
}

\begin{abstract}
Resumen
Las investigaciones sobre la interdicción y su expresión han llevado a que solo es posible un profundo acercamiento a este fenómeno mediante un análisis simultáneo desde diferentes ámbitos lingüísticos y extralingüísticos. En esta línea nuestro trabajo considera la expresión de las realidades y conceptos interdictos en el discurso oral de los hablantes malagueños. Atendemos a determinadas variables pragmático-discursivas (expresión, finalidad, función) así como a las características sociolingüísticas (sexo, edad, instrucción) de estos hablantes para conocer cuál es su actuación ante los conceptos tabuizados. Consideramos así el uso y frecuencias de expresiones referidas a realidades interdictas en el habla de Málaga, los recursos que aparecen en estas
\end{abstract}

\begin{abstract}
Research on interdiction and its expression have led to the fact that a deep approach to this phenomenon is only possible through a simultaneous analysis from different linguistic and extralinguistic fields. In this line, our work considers the expression of the forbidden realities and concepts in Malaga speakers' oral discourse. We attend to certain pragmatic-discursive variables (expression, purpose, function) as well as the sociolinguistic characteristics (sex, age, education) of these speakers to know what their performance is in tabooed concepts. Thus, we consider the use and frequencies of expressions which refers to forbidden realities in the speech of Malaga, the resources that appear in these expressions linguistics, their discursive function and purpo-
\end{abstract}

Este trabajo ha sido posible gracias a la financiación por el Ministerio de Ciencia e Innovación del Proyecto Patrones Sociolingüísticos del Español de Málaga (PASOS-MA), FFI2011-29189-C05-01, 2012-2014. Se ha beneficiado asimismo de la ayuda concedida al Proyecto de Estudio Complementario de los Patrones Sociolingüísticos del Español de Málaga (ECOPASOS-MA), FFI2015-68171-C5-1.

Para citar este artículo: Guerrero Ramos, Gloria y Pérez Lagos, Manuel Fernando (2021). La expresión del tabú en el habla de Málaga. ELUA, 35: 125-162. https://doi.org/10.14198/ELUA2021.35.7

Recibido: 05/10/2020, Aceptado: 08/11/2020

(C) 2021 Gloria Guerrero Ramos, Manuel Fernando Pérez Lagos

Este trabajo está sujeto a una licencia de Reconocimiento 4.0 Internacional

de Creative Commons (CC BY 4.0) 
expresiones lingüísticas, su función discursiva y finalidad y, además, mostramos la variabilidad del fenómeno atendiendo a tres tradicionales variables sociolingüísticas: edad, sexo, estudios del hablante malagueño. Comparamos también los resultados de nuestro estudio con los obtenidos por los grupos PRESEEA de Madrid y Granada.

PALABRAS CLAVE: discurso, tabú; eufemismo; disfemismo; interdicción; variables pragmático-discursivas; variables sociolingüísticas. se and, in addition, we show the variability of the phenomenon attending to three traditional sociolinguistic variables: age, sex, studies of the Malaga speaker. We also compared the results of our study with those obtained by Madrid's and Granada's PRESEEA groups.

KEYWORDS: discourse, taboo, euphemism, dysphemism, interdiction, pragmaticdiscursive variables, sociolinguistic variables

\section{MARCO TEÓRICO O ESTADO DE LA CUESTIÓN}

Casas (2012a) distingue dos caracterizaciones sobre el fenómeno eufemístico: una extralingüística y otra lingüística. Dentro de esta última también incluye la dimensión pragmática del fenómeno, que algunos (como Crespo 2007) suelen separar y que él considera puramente lingüística, pues, al fin y al cabo, la pragmática es una "semántica del hablar".

Aunque no nos vamos a detener en las diversas clasificaciones del fenómeno que se han realizado, sí que debemos reconocer desde el principio que estamos ante un tema de estudio tanto lingüístico como extralingüístico (Casas 1986: 64), aspectos estrechamente imbricados en el análisis que nos ocupa. No es suficiente, por ejemplo, con estudiar los eufemismos como un tipo de palabras con una serie de características, lo importante es contemplarlos como fruto de una estrategia comunicativa en el plano del discurso. $Y$ es que, tal como ha señalado Casas (1986: 40-41), "el matiz eufemístico de una palabra es, consiguientemente, inestable, efímero y relativo; ofrece [...] diferencias sustanciales según la época, lugar, pueblo, clase social, sexo, edad y circunstancias".

En realidad, algunos de los planteamientos del eufemismo como un fenómeno léxico de sustitución de otro vocablo prohibido están más próximos a lo extralingüístico que a lo lingüístico, pues se basan en los motivos, en las causas que los producen o en las finalidades que pretenden, muchas veces de tipo psicológico, pero no en su naturaleza lingüística. De esta manera, cuando Ullmann (1976: 230-236) se ocupa de las causas del cambio semántico, recoge el tabú entre las causas psicológicas y distingue tres tabúes de lenguaje (tabú del miedo, tabú de la delicadeza y tabú de la decencia) atendiendo a la motivación psicológica que hay tras ellos (miedo, respeto y pudor, respectivamente). Por ello, el eufemismo es visto por este autor como el "sustituto inofensivo" de la palabra tabú que ha de ser abandonada.

También Coseriu, hablando de la creación metafórica en el lenguaje (Coseriu 1991: 66102), nos dice que, en el lenguaje, junto a las relaciones significativas, morfológicas y sintácticas, existen otras relaciones entre las palabras, debidas a "asociaciones subjetivas y metafóricas" (p. 89). Entre las razones que determinan eso que llama "fantasía humana creadora", provocadora de la sustitución de signos y de la invención de otros, Coseriu nos coloca al tabú.

Su definición de tabú lingüístico es ampliamente conocida y citada: "fenómeno por el cual ciertas palabras relacionadas con supersticiones y creencias se evitan y se sustituyen por préstamos, eufemismos, circunlocuciones, metáforas, antífrasis, etc." (Coseriu 1991: 90). Como se ve, se centra en el plano de las palabras (palabras que se quieren evitar) y explica la existencia de este tabú lingüístico por la creencia de lo que llama "la magia de las palabras", basado en esa concepción arraigada en las sociedades primitivas (ya planteada en 
los filósofos griegos) que identificaba el nombre y la cosa nombrada ("nombrar la cosa trae consigo la cosa misma" (p. 91)). Encontramos en esto último el motivo, la razón principal del eufemismo: si queremos evitar los "denotata" sujetos a tabú, buscaremos expresiones o palabras que los nombren, pero "sin nombrar", como dirá Coseriu, dándose satisfacción con ello a la necesidad del hombre de hablar de aquello que está prohibido hablar.

Además, Coseriu no se refiere solo al tabú lingüístico, no sólo a las razones de superstición y creencias, sino también a otras razones de índole "emotiva o social", a un fenómeno más amplio que llama "interdicción de vocabulario", un fenómeno que lleva a evitar expresiones y palabras que "se consideran demasiado crudas, o descorteses, o indecentes" (1991: 93). De esta manera, los procedimientos que nos ofrece el lenguaje adquieren valor eufemístico solo cuando hay detrás cierta coacción externa, sea social o psicológica, cuando hay, en definitiva, interdicción. Parece que, aunque Coseriu se limita al ámbito del vocabulario, sí que atiende al aspecto externo o extralingüístico que provoca el fenómeno.

Para las caracterizaciones del fenómeno eufemístico desde una perspectiva puramente lingüística, Casas (2012a: 57-61) muestra una evolución en su tratamiento teórico desde el marco de una semántica léxica estructural hasta llegar a las "más modernas consideraciones pragmático-discursivas y, más recientemente de carácter cognitivista” (p. 57. Ver más recientemente Casas, 2018).

En primer lugar, en cuanto a las caracterizaciones léxicas del fenómeno, tendríamos que mencionar aquellos autores que, desde la semántica léxica, hablan de pérdida o de exclusión de semas o rasgos semánticos considerados tabú: "atenuación por ocultación de rasgos" (Alonso 1988: 78). Atienden, por tanto, a la mutación o extensión de significado que se produce en el eufemismo (Chamizo y Sánchez 2000: 37) y a su posible acercamiento al fenómeno de la sinonimia cuando dejan de ser actualizaciones de una referencia infrecuente y pasan a significar lo mismo que la expresión eludida (Martín 1994: 337).

No podemos, sin embargo, equiparar tan a la ligera el sustituto sinonímico con el sustituto eufemístico (Ver Casas 1995), pues no hay que olvidar que en el fenómeno del eufemismo no estamos en el plano de la lengua sino en el del discurso, no hay "palabras eufemismos/disfemismos sino solo usos eufemísticos/disfemísticos" (Casas 2012a: 60), $\mathrm{y}$, por tanto, asumen ese uso cuando el hablante-oyente lo comprende como adecuado sustituto en determinado contexto y en determinada situación, en el que "denotan pero no connotan lo mismo" (Montero 1981: 26).

Por otro lado, Horak (2012: 48) considera que la perspectiva más adecuada para examinar el eufemismo es de naturaleza pragmática, pues es la única, dice, que permite tener en cuenta todos los aspectos ligados a la producción y recepción del discurso eufemístico. En realidad, todos los trabajos que se ocupan del fenómeno desde esta perspectiva lo tratan como una muestra de uso comunicativo que genera una determinada consecuencia en el oyente.

Desde estas últimas perspectivas los eufemismos nacen por la necesidad del hablante de eliminar todo aquello que pueda provocar disgusto o aversión en el oyente y que, en definitiva, deteriore la interrelación entre los hablantes debido a una posible descortesía. El hablante no quiere ser ofensivo en su uso comunicativo y adopta una estrategia que lo evite. Una de estas estrategias puede ser la de la máxima de la cortesía, "especialmente la de respetar el derecho del oyente a no ser herido o molestado, siempre que no se pierda la inteligibilidad del mensaje, ni la sinceridad, propias de la máxima de calidad" (Alcaraz y Martínez 1997: 220). De esta manera, cuando Escandell Vidal (2014) se ocupa de la 
cortesía comunicativa, nos la presenta como una estrategia conversacional destinada a evitar conflictos y nos dirá que el eufemismo no es más que una estrategia del lenguaje para proteger la imagen de los comunicadores. Y es que no podemos olvidar el origen y la necesidad del eufemismo: existencia de temas tabúes de los que no se puede hablar y que, a la vez, en ocasiones hay que mencionar (recuérdense los planteamientos de Freud de aversión y atracción hacia lo prohibido).

En realidad, cuando desde la pragmática lingüística se presenta el concepto de implicaturas, se está hablando de "determinados modos de expresión implícita, que permitan dar a entender algo sin incurrir en la responsabilidad de haberlo dicho" (Ducrot 1982: 11). La conexión del eufemismo con estos 'modos de expresión implícitos' es evidente, del mismo modo que con otro de los conceptos desarrollados por la pragmática: las presuposiciones. Sólo que en estas últimas el hablante es responsable de sus contenidos, pues están basados en el significado literal, mientras que las implicaturas dependerán siempre de la interpretación del oyente, y el hablante siempre podrá decir que él no ha dicho eso (Martín 1994: 327). Se comprueba así la índole eufemística de la implicatura: en esta el hablante viola alguna máxima del principio de cooperación con la intención de aportar al oyente una información extra que no está en el enunciado, mientras que la razón de ser del eufemismo es la de evitar la mención directa de algo que se considera desagradable.

Sin embargo, nos parece, como a Martín (1994), que, si bien toda implicatura contiene rasgos eufemísticos, no todo eufemismo contiene implicatura. Por eso el estudio de esta "no da cuenta de la gran variedad de eufemismos utilizados en el uso común del lenguaje, ni es un análisis suficiente para explicar el valor eufemístico" (Martín 1994: 329). En definitiva, la conexión del eufemismo con los aspectos a los que presta atención la pragmática, especialmente en cuanto a los actos de habla indirectos o de desviación del decir, no significa que esta disciplina lingüística pueda dar cuenta por sí sola del fenómeno eufemístico.

Gran parte de los trabajos más recientes parecen coincidir en que estamos ante un fenómeno discursivo en el que los factores sociales y lingüísticos que lo constituyen se actualizan dentro de un determinado contexto y situación pragmática (Crespo, 2007: 82). El fenómeno eufemístico se caracteriza desde entonces como un proceso (así diferenciado de la unidad sustituta) en el que se rompen las asociaciones establecidas entre el tabú y su expresión lingüística mediante un acto de habla (unidad sustituta) que pone de manifiesto la intención de huir del tabú, siempre dentro de determinada situación pragmática y contexto discursivo.

Casas (2012a) propone dar un paso más y, tras hacer una revisión autocrítica de lo postulado en su monografía (Casas, 1986) y trabajos derivados, demuestra la necesidad de atender al fenómeno eufemístico desde una visión cognitiva. No es suficiente que lo consideremos solo como un fenómeno pragmático-discursivo dentro de una lingüística de la comunicación, ni que quede caracterizado como una serie de mecanismos lingüísticos que permiten la comunicación atenuada de formas lingüísticas interdictas. Ya no se trata de entenderlo como una expresión atenuada sino como un proceso de atenuación, y este proceso hay que enfocarlo no desde el término interdicto, sino desde el contenido o realidad interdicta. Ahora se trata de una actividad onomasiológica del emisor que conceptualiza la realidad interdicta y se acerca a ella de manera eufemística o disfemística según determinada situación pragmática.

Creemos que se llega así a la más completa definición lingüística del eufemismo o el disfemismo que conocemos: 
proceso cognitivo de conceptualización de una realidad interdicta, que, manifestado discursivamente a través de la actualización de un conjunto de mecanismos lingüísticos de sustitución léxica, alteración fonética, modificación, composición o inversión morfológica, agrupación o combinatoria sintagmática, modulación verbal o paralingüística o descripción textual, permite al hablante, desde un punto de vista comunicativo en el que tiene presente la posible interpretación del oyente por los efectos perlocutivos que los usos eufemísticos/disfemísticos pueden provocar en los interlocutores, la creación intencional de todo tipo de expresiones verbales y no verbales o actos de habla, que, en un cierto «contexto» y en una concreta situación pragmática, encubren, atenúan o realzan expresivamente, $o$, por el contrario, motivan o refuerzan evocativamente un determinado concepto o realidad interdicta (Casas 2012a: 68-69).

En esta definición se ofrece un enfoque totalmente renovado del fenómeno, caracterizando de forma orquestada desde importantes corrientes lingüísticas sus principales aspectos:

- Principalmente, que es un proceso cognitivo (conceptualización de la realidad interdicta).

- Que tiene una manifestación discursiva (no de lengua) mediante diferentes mecanismos lingüísticos (no solo de sustitución léxica sino hasta de descripción textual -todo un hablar eufemístico o disfemístico-).

- Que permite al hablante un acto de habla que atenúa o refuerza el concepto interdicto. Para ello intervienen:

o la consideración de la posible interpretación del oyente (efectos perlocutivos)

o y la intencionalidad de la creación para determinado contexto y situación pragmática.

Esta nueva perspectiva conlleva la reconsideración conceptual de casi todos los términos y nociones que se han venido empleando para el tratamiento de este fenómeno del lenguaje, especialmente, para llegar a la diferenciación entre tabú de palabra y tabú de concepto o interdicción conceptual (Casas 2012a: 67). Repasaremos por ello las precisiones lingüísticas que, desde el ámbito conceptual, ha recibido el conjunto de unidades terminológicas propias del campo de la interdicción. Seguiremos la presentación que de ellas hace Casas (2005 y, más recientemente, 2018).

Como ya hemos visto no es lo mismo eufemismo que sustituto eufemístico. Es frecuente que se emplee el primero para referirse al término que reemplaza al vocablo interdicto y no para referirse al proceso o fenómeno de reemplazo. La interpretación como sustitución léxica de los inicios ha llevado a que se atienda el tema del eufemismo desde el nivel de la palabra y a que solo más adelante se atiendan también otros niveles de análisis.

Los sustitutos eufemísticos, generalmente sustitutos léxicos, pero no siempre, suponen que la norma lingüística proponga, para el uso general de los hablantes y para cada área conceptual interdictiva, unos sustitutos lexicalizados con capacidad eufemística (Casas 2005: 274). Sin embargo, si ya sabemos que hablamos de un fenómeno discursivo, un acto de habla, cargado, por tanto, de relatividad e inestabilidad, no se puede afirmar, en realidad, la existencia de palabras-eufemismos, sino de usos eufemísticos "creados momentáneamente y esporádicamente por los usuarios en determinados contextos situacionales" (2005: 274).

También precisan aclaraciones las nociones de tabú y de interdicción. Ya hemos visto más arriba cómo Coseriu (1991: 93) distingue entre tabú e interdicción considerando el 
primero como un aspecto del fenómeno más amplio que es el segundo. De esta manera el tabú lingüístico queda restringido al ámbito de lo sobrenatural y religioso, de las supersticiones y creencias, mientras que la interdicción, "como fenómeno más totalizador, abarca [también] otras coordenadas sociales, sexuales, escatológicas, etc.” (Casas 2012a: 66). No se debe admitir, por tanto, la frecuente extensión del sentido que se hace equiparando tabú con interdicción, cuando, en el primer caso, hablamos de la esfera mágico-religiosa (con motivaciones internas y psíquicas) y en el segundo, en el de la interdicción, hablamos de las demás facetas de la vida social (de naturaleza afectivo-asociativa) (Casas 2005: 281).

A partir de la distinción anterior, Casas (2000) diferencia entre tabú de palabra e interdicción conceptual. El primero está basado en la creencia ancestral del poder mágico de la palabra que produce aquello que designa, en una identificación en el ámbito mágico-religioso de la palabra con la cosa. Se trata, por tanto, de palabras tabúes que, identificadas con los objetos interdictos, se eluden reemplazándolas mediante un proceso (generalmente léxico) de sustitución eufemística. En el caso, sin embargo, del tabú de concepto o de interdicción conceptual no se parte necesariamente de la existencia léxica de un término interdicto, sino que es a partir del concepto o realidad interdicta desde donde se plantean los procesos eufemísticos o disfemísticos. Ya Uría Varela (1997: 6) advertía de realidades interdictas que parecían carecer de término tabú de base, lo que obliga a abandonar los planteamientos tradicionales sobre el fenómeno desde el plano léxico y acercarnos a él desde un proceso cognitivo de conceptualización de una realidad interdicta (Casas 2005: 284).

Después de todas estas aclaraciones terminológicas y conceptuales, y volviendo a la definición de Casas, comprendemos mejor la relatividad e inestabilidad del fenómeno tantas veces mencionada. El proceso de conceptualización descrito estará siempre vinculado a la creación de un acto de habla particular (y momentáneo) y determinado por el hablante, los oyentes, las "circunstancias de tiempo y lugar, cultura, ideología, sexo, edad, relaciones sociales, situación de comunicación, etc.” (Casado 2015: 105-106). Por eso Casas nos advierte que no están tan claras las fronteras entre lo eufemístico y lo disfemístico, y que, en la mayor parte de los casos, que una variante es un eufemismo o un disfemismo depende de la intencionalidad y el contexto en el que se produzca (Casas 2005: 278-279). La distinción entre ambos conceptos no depende solo de la situación pragmática, que es fundamental, sino que también hay que considerar la entonación o los gestos que nos pueden revelar la verdadera intención comunicativa del interlocutor. Así nos habla de las connotaciones eufemísticas que pueden tener los disfemismos y de las connotaciones disfemísticas que pueden encontrarse en algunos eufemismos, mostrando la ausencia de una línea marcada sobre la distinción de ambos procesos.

Estos actos de habla "momentáneos y esporádicos" creados por el hablante ya hemos comentado que han de ser atendidos desde diferentes perspectivas lingüísticas y extralingüísticas. Entre ellas hemos destacado la visión discursivo-pragmática cuando los trabajos se interesan por la intencionalidad de desviación del decir por parte del hablante, sus estrategias de cortesía (de respeto y de ser respetado), la interpretación que ha de realizar el oyente, etc. Lo que no hemos destacado, y hemos dejado para el final, es la posibilidad, y necesidad, de analizarlos también desde una perspectiva claramente sociolingüística, pues siempre que hemos hablado de contexto y de situación debemos considerar la influencia, la presión que, tanto uno como otra, suponen para la creación de ese acto de habla.

Como se sabe, desde la sociolingüística no sólo se describen los fenómenos lingüísticos, sino que además estos se intentan explicar atendiendo a los factores y elementos externos al 
sistema lingüístico, como son el contexto, la situación comunicativa, las variables sociales tales como la edad, el género, el nivel de instrucción, etc., que los determinan. Así pues, desde esta perspectiva interesa tanto el eufemismo como su creador y sus características socioculturales.

Entre los trabajos que abordaron el fenómeno que nos ocupa desde esta perspectiva, cabe destacar, por pioneros, los de López Morales (1990, 1997, 2001, 2005). Nos dice Calvo Shadid (2011: 134) que "el autor parte de la premisa de que el uso del tabú está condicionado, al menos, por el estrato sociocultural del hablante y por el estilo empleado en la interacción lingüística." López Morales destaca que las unidades tabuizadas, las eufemísticas y las no marcadas, si dejáramos al margen estas condicionantes sociales, funcionarían como sinónimos perfectos en cualquier contexto. De esta manera, pone en relación una serie de expresiones lingüísticas de realidades claramente tabuizadas con las características del tipo sexo, edad y estrato social presentes en los miembros de una comunidad de hablantes, como la de San Juan de Puerto Rico, además del planteamiento de tres situaciones de uso (espontáneo, cuidadoso o neutral), para determinar en qué medida las condiciones sociales influyen en la elección de esas expresiones.

A partir de la metodología propuesta por López Morales, se realizaron otras investigaciones desde esta perspectiva sociolingüística. Así, por ejemplo, Martínez Valdueza (1995) recoge una serie de lexemas tabuizados del ámbito sexual y atiende a su expresión por parte de una muestra de hablantes de español de Las Palmas de Gran Canarias; los divide por sexos, edad y niveles de estudio, además de considerar para el nivel sociocultural la instrucción, la profesión y los ingresos y de establecer tres situaciones de comunicación para cada uno de los tres estilos.

Por otra parte, Calvo Shadid (2009) se ocupa de la sociolingüística del tabú sexual en el español de Costa Rica. A partir de una serie de lexías sexuales tabuizadas, realiza su análisis desde variables sociolingüísticas como las de sexo, edad, nivel de instrucción y nivel socioeconómico. Aparecen también en su trabajo los primeros análisis comparativos entre los resultados de la comunidad que estudia y los resultados a los que llegaron López Morales (1990), para la comunidad de San Juan de Puerto Rico, y Martínez Valdueza (1995) para Las Palmas de Gran Canaria.

Si bien estos últimos trabajos ya no siguen el planteamiento tradicional de descripción del fenómeno a partir de textos generalmente literarios y usan la metodología de las encuestas y entrevistas orales, lo cierto es que se limitan a la esfera de la sexualidad. Podemos considerar el trabajo de Cestero (2015) como el primero que, desde esta perspectiva sociolingüística, procura atender a las diferentes esferas conceptuales en las que opera el tabú y a las expresiones lingüísticas orales que lo representan. Para ello propone un marco metodológico de análisis que establece cuatro categorías, correspondientes con las esferas propuestas por Montero (1981): la esfera mágico-religiosa, la sexual, la escatológica y la social. Cada una de ellas tiene una causa psicológica que las motiva: el miedo, la decencia, el pudor y el respeto, respectivamente. Destaca también en su planteamiento el que, como estos grupos no pueden ser considerados de forma aislada por estar siempre inmersos en un contexto, atiende a variables pragmáticas como la función comunicativa (referencial, no referencial, apelativa, expresiva y marcadora de estilo) y la finalidad (encubrir, atenuar, realzar e informar). Desde esta sistematicidad aborda el análisis sociolingüístico de la expresión oral de las realidades interdictas a partir del material que le ofrece el corpus PRESEEA sobre el habla de Madrid llevado a cabo en la Universidad de Alcalá. 
La configuración del macroproyecto PRESEEA, y su realización con las mismas pautas en diferentes áreas locales, propicia no sólo el análisis sociolingüístico del material recogido, sino que facilita la comparación de los resultados obtenidos en los estudios de cada uno de los corpus locales. Así, Jiménez (2016), para su estudio del tabú en el habla de Granada, trabaja con el corpus PRESEEA llevado a cabo en la Universidad de Granada y sigue los mismos pasos propuestos por Cestero (2015): aparte de las variables sociales propias del tipo de corpus creado, incluye las variables pragmáticas de interdicción, expresión, finalidad y función "dada la interdependencia que existe entre la expresión del tabú y su contexto comunicativo" (Jiménez 2016: 31).

Dentro de este grupo de estudios de carácter sociolingüístico debemos destacar, por sus repercusiones, el trabajo de Pizarro (2013), un enfoque integrador de todas las investigaciones anteriores de corte pragmático-discursivo con otros factores de corte socio-cognitivo. En el desarrollo de su investigación doctoral la autora ha dejado planteadas las bases, tanto teóricas como metodológicas, para el estudio del tabú desde la sociolingüística cognitiva. Deja claro, en definitiva, que en el proceso eufemístico y sus estrategias hay implicados factores sociales y contextuales que son determinantes, pero también lo son otros componentes como los de las características de personalidad e identidad del hablante. En esta línea de atención al tabú y la identidad del hablante que actúa ante los mismos, se podrían incluir también los enfoques desde una perspectiva de género. Así, por ejemplo, Guerrero $(2007,2012)$ se ocupa de las diferencias lingüísticas entre los sexos en sus usos eufemísticos.

\section{NUESTRO ESTUDIO}

\subsection{Objetivos}

Continuamos en este trabajo la línea iniciada por Cestero (2015) y continuada por Jiménez (2016): estudiamos las expresiones lingüísticas utilizadas por los hablantes malagueños para referirse a alguna realidad interdicta a partir del corpus PRESEEA llevado a cabo en la Universidad de Málaga.

Además de este objetivo general de cuál es la actuación ante los conceptos tabuizados que tiene el hablante malagueño, tenemos unos objetivos específicos similares a los atendidos por los otros dos grupos de PRESEEA mencionados:

- Saber el uso y frecuencia de expresiones referidas a realidades interdictas en el habla de Málaga.

- Conocer qué recursos aparecen en estas expresiones lingüísticas, así como su función discursiva y finalidad.

- Dar cuenta de la variabilidad del fenómeno atendiendo a las tres tradicionales variables sociolingüísticas: edad, sexo, estudios.

- Comparar los resultados de nuestro estudio con los de otros grupos PRESEEA.

\subsection{Metodología}

En el corpus del español hablado en Málaga (Vida 2007; Ávila, Lasarte y Villena 2008 y Lasarte, Sánchez, Ávila y Villena, 2008), la metodología que se sigue en su construcción es la propuesta en el macroproyecto PRESEEA inicial (Moreno 2003), al igual que han hecho todos los equipos miembros encargados de otras áreas dialectales del español. 
De esta manera, para que la muestra reunida en uno de los equipos sea comparable con el resto, todos los grupos adscritos al macroproyecto han seguido los mismos criterios: estructuración del núcleo poblacional atendiendo a tres parámetros sociales: edad, sexo y nivel de estudios; cuotas con afijación uniforme y material oral recogido en conversación semidirigida:

la muestra-tipo diseñada para el PRESEEA distingue, en primer lugar, tres grandes grupos generacionales: el primero estaría formado por sujetos de entre 20 y 34 años de edad, el segundo por informantes de entre 35 y 54 años y el tercero por sujetos de más de 55 años. En segundo lugar, la población se divide por sexos: hombres y mujeres y, por último, se distinguen tres niveles de instrucción: primaria (0-10 años aproximadamente de escolarización), secundaria (unos 10-14 años de estudios) y superior (15 años de escolarización aproximadamente) (Vida, 2007: 24).

El corpus de Málaga registra la información de cuatro informantes por cada uno de los posibles apartados de la anterior estructuración, lo que supone la suma de 72 entrevistados para la muestra.

\begin{tabular}{|l|c|c|c|c|c|c|}
\hline & \multicolumn{2}{|c|}{$\begin{array}{c}\text { Generación 1 } \\
\text { (menos de 34) }\end{array}$} & \multicolumn{2}{c|}{$\begin{array}{c}\text { Generación 2 } \\
\text { (entre 35 y 54) }\end{array}$} & \multicolumn{2}{c|}{$\begin{array}{c}\text { Generación 3 } \\
\text { (más de 55) }\end{array}$} \\
\hline & Hombres & Mujeres & Hombres & Mujeres & Hombres & Mujeres \\
\hline $\begin{array}{l}\text { Estudios } \\
\text { Básicos }\end{array}$ & 4 & 4 & 4 & 4 & 4 & 4 \\
\hline $\begin{array}{l}\text { Estudios } \\
\text { Secundarios }\end{array}$ & 4 & 4 & 4 & 4 & 4 & 4 \\
\hline $\begin{array}{l}\text { Estudios } \\
\text { Superiores }\end{array}$ & 4 & 4 & 4 & 4 & 4 & 4 \\
\hline
\end{tabular}

Tabla 1. Informantes corpus de Málaga

Los datos reunidos son a partir de las grabaciones de las conversaciones semidirigidas realizadas. Como se sabe, en este tipo de entrevistas el entrevistador sólo estimula la participación de los informantes mediante la propuesta de algunos temas de guía de conversación. Es cierto que, ante una conversación que está siendo grabada, el entrevistado tiende hacia la formalidad, y solo será la pericia del entrevistador la que logre más o menos momentos de espontaneidad. Reconocemos, por tanto, que, pese a la novedad e importancia de tratarse de información procedente del discurso oral, en muchas ocasiones estaremos ante expresiones propias de un registro semiformal.

\subsection{Variables}

Tal y como hemos ido mostrando en el apartado del estado de la cuestión, nuestro estudio ha de procurar tener en consideración no solo la clara interdependencia existente entre la interdicción y el contexto, sino que también han de intervenir factores pragmáticos. Así, nuestra investigación ha de combinar, como dice Cestero (2015b: 79), "el análisis de la conversación, la pragmática y la sociolingüística, sin olvidar, lógicamente, las aportaciones que se han hecho sobre el tema desde la semántica léxica y la pragmática cognitiva”. 
Entre las variables que consideraremos, por tanto, no estarán solo las tradicionales variables sociales propias de un estudio sociolingüístico, sino también una serie de variables pragmáticas y discursivas.

\subsubsection{Variables sociolingüisticas}

Las variables sociolingüísticas que hemos considerado, como ya hemos apuntado atendiendo a las características de nuestro corpus, son:

\subsubsection{1. generación / edad}

Distinguimos tres grupos generacionales siguiendo las consideraciones generales del PRESEEA: uno, de 20 a 34 años; otro de 35 a 54 años; y un tercero a partir de 55 años.

\subsubsection{2. sexo}

Atendemos, como es habitual en las investigaciones sociolingüísticas, a si la expresión lingüística ha sido realizada por un hombre o por una mujer.

\subsubsection{3. nivel de instrucción}

También aquí seguimos las propuestas del PRESEEA y distinguimos tres grados de instrucción en nuestros encuestados: un nivel básico o primario, un nivel secundario y un nivel superior.

Recordemos que el número de encuestados en cada una de estas diferentes agrupaciones ha sido siempre equitativo.

\subsubsection{Variables pragmáticas y discursivas}

Hemos considerado, guiados por Cestero (2015) y Jiménez (2016), las siguientes:

\subsubsection{Interdicción}

En primer lugar, hemos necesitado disponer de una ordenación de los dominios de la realidad que son prohibidos. Generalmente, se suelen distinguir los tipos de tabú atendiendo a las causas psicológicas que los motivan: miedo, pudor o respeto (Ullmann 1976; Crespo 2007), y los efectos como las diferentes categorías de tabú que pueden establecerse. Seguimos estos planteamientos, pero teniendo en cuenta la adaptación de Pizarro (2013: 75), que procura desvincular las causas de las categorías, pues piensa que cualquiera de las tres causas (miedo, pudor, respeto) puede ser motivadora de alguna de las categorías (y subcategorías) establecidas.

De todas maneras, aunque siempre tengamos presentes las anteriores consideraciones, hemos querido en nuestro estudio mantener la misma clasificación de la interdicción seguida por Cestero (2015) y, también, después, por Jiménez (2016), las dos guiadas por Montero (1981), para, de esta manera, poder realizar las comparaciones oportunas entre los diferentes corpus orales locales. 
Consideramos, por tanto, cuatro esferas básicas de interdicción ${ }^{1}$ :

1. esfera mágico-religiosa (miedo): en ella entra desde el tabú más ancestral religioso hasta la muerte e incluso la enfermedad

2. esfera sexual (decencia): en esta interdicción se considera desde partes erógenas del cuerpo hasta las prácticas sexuales

3. esfera escatológica (pudor): desde la evacuación de fluidos escatológicos hasta los lugares para hacerlo

4. esfera social (respeto): en ella se incluye toda realidad considerada indeseable, desde diferencias físicas y defectos psíquicos, hasta situaciones socioeconómicas.

Sin duda, dentro de cada una de estas esferas es posible establecer diversos subapartados a partir de las diferentes clasificaciones sobre las áreas tabuizadas que han realizado numerosos investigadores (como Casas (1986), Crespo (2007), Montero (1981) y otros). Mediante los ejemplos de cada una de las esferas, que a continuación mostramos, destacamos las diferentes subesferas que hemos encontrado en nuestro corpus.

\section{1. esfera mágico-religiosa}

(1a) deidad

hay... más mujeres que hombres, pero ¡vamos! vamos gracias a Dios vamos bien 002/60M1/AMA DE CASA

terminaría si Dios quiere con cincuenta años de trabajo entonces vamos pues y luego pues qué haría pues no sé 716/63H3/INGENIERO INDUSTRIAL

yo decía ay Dios mío eran unos tiempos muy malos y eran unos tiempos muy difíciles 720/64M3/MAESTRA

(1b) muerte

mi padre murió cuando estábamos en Nador estaba en el Instituto árabe de Nador. 711/53M3/ADMINISTRATIVA

la sobrina es que se le mataron los padres y entonces vive mucho lleva muchos años viviendo con ellos. 046/28M3/PROFESORA

ya mi abuelo había fallecido y la muchacha que había tenido siempre mi abuelo una de ellas se vino con nosotras. 711/53M3/ADMINISTRATIVA

(1c) enfermedad

iba con mi primo y le dio un infarto de estos de miocardio, pero fulminante que fue caer al suelo y y vamos muerto 727/61H2/COMERCIANTE

1 Seguimos la cuatro grandes esferas tradicionales y, para futuros trabajos, hacemos las diferentes distinciones que los investigadores establecen dentro de ellas. Sabemos que actualmente se atiende mucho a otras esferas como la esfera político-social y la expresión políticamente correcta de sus conflictos, pero en este trabajo, como en los otros dos grupos de PRESEEA con los que lo compararemos, analizamos solo las cuatro esferas tradicionalmente reconocidas. 
por lo visto llegó malísima malísima vamos que se moría y se levantó 704/43M2/AMA DE CASA

trabajaba de como de enfermero se colocó en el Banco Hispano y allí estuvo treinta y un años en el Banco Hispano hasta que se enfermó y y estuvo seis años enfermo hasta que murió. 009/80M1/AMA DE CASA

y de pronto te acuerdas ay que fulanito tenía el hijo malo y un momento ¿tu hijo está mejor? 711/53M3/ADMINISTRATIVA

\section{2. esfera sexual}

(2a) partes del cuerpo relacionadas con el sexo

lo pago con un año después y cuando me sale los cojones y me merece la pena $012 / 38 \mathrm{H} 2$ / ADMINISTRATIVO

yo soy Alfonso Gallardo Fernández treint y ocho años y malagueño y punto ¡claro! ¡coño! si es que lo ha contao to. 012/38H2/ADMINISTRATIVO

y estamos hablando el inspector y el inspector está hasta peor que nosotros está hasta los mismísimos dice que le llegan los problemas por abajo y por arriba ¿me explico? 732/28H3/PROFESOR ENSEÑANZA SECUNDARIA

(2b) prácticas sexuales

yo decía tú verás que en cualquier momento va a bajar y la va a forzar o hacer algo y yo todo el rato sufriendo porque a mí esas escenas no me gusta verlas 721/61M2/AMA DE CASA

con la reforma sí tenemos mucho que exigi nos están dando mucho por culo. 00527H3PROFESOR ENSEÑANZA SECUNDARIA

no lo ve y entonces lo que dicen es que a nosotros nos jodemos porque eso es pa lo que no están pagando pa que aguantemos 732/28H3/PROFESOR ENSEÑANZA SECUNDARIA

nada nací yo después nació mi hermana Mari Carmen a mí me encargaron a ver septiembre octubre después de casaos 732/28H3/PROFESOR ENSEÑANZA SECUNDARIA

(2c) efectos de prácticas sexuales

sí nada nada nada nació el primero y a los dos meses y pico me quedé embarazada del segundo como yo digo también sin sin saber ni como vaya sabiendo 718/47M3/PROFESORA ENSEÑANZA SECUNDARIA

lo que es la gente que aborta por gusto y tal y cual y ella la pena tan grande de aquel aborto que tuvo yo me acuerdo mucho cuando veo en la televisión que la gente aborta por gusto 704/43M2/AMA DE CASA

(2d) personas implicadas en prácticas y conductas sexuales pero antes antes el hombre que le ayudaba a las mujeres le decían mariquita y tú comprenderás... hoy no hoy no hoy ... hoy no. 001/64H1/PENSIONISTA DUEÑO DE UN BAR 
luego me fui a la mili de prórroga allí trabajé dos a... doce meses pa los hijos de puta del gobierno 012/38H2/ADMINISTRATIVO

ahora la carta de pago la contribución yo tengo que ser el cabrón de turno que me tenga que molestar ¡qué se molesten ellos! 012/38H2/ADMINISTRATIVO

\section{3. esfera escatológica}

(3a) actos de evacuación

cuando lo del remolque vamo con la roulotte voy al ayuntamiento eso es pa cagarse una 012/38H2/ADMINISTRATIVO

y se orinaba piernas abajo pero como ahora se lo toman a risa porque no yo opino que no hay castigo para estos señores pues hacen muy bien 111/55M1/AMA DE CASA

pues cuando me di cuenta estaba haciendo pipí pues estaba metia en el cuarto baño los niños menos mal menos mal que no entró nadie ni nada 075/25M1/DEPENDIENTE DE COMERCIO

(3b) residuos escatológicos

nos habíamos adaptao la mierda a nosotros y nosotros a la mierda y nos encajábamos bien y no había mayores problemas 708/61H3/INGENIERO AGRÓNOMO

el ayuntamiento ha repartido hasta guantes bolsitas para coger las las cosas de los perros la caquita y meterla en la bolsita 730/35H2/ADMINISTRATIVO

(3c) lugares para evacuar

entonces pues me acuerdo de eso que me entró muchas ganas de ir al servicio 075/25M1/ DEPENDIENTE DE COMERCIO

sí porque estaban los los váter allí en el patio los váter con las puertas abiertas. 002/60M1/ AMA DE CASA

\section{4. esfera social}

(4a) situaciones y diferencias socioeconómicas pues ahora mismo estamos más desahogaos al principio nos hemos tirao un par de años cuando nos compramos la casa un poquito más asfixiaos y llegué un momento... 026/28H2/ REPRESENTANTE

y nos traía muchas cosas de Gibraltar porque nosotros en aquel entonces gracias a Dios éramos una familia no rica una familia no rica pero pero acomodada 727/61H2/COMERCIANTE

sí los más necesitaos del barrio además vamos a hacer una rifa también con una canastilla y y el dinero que cada uno acepta ahora pa los más necesitaos del barrio. 001/64H1/PENSIONISTA DUEÑO DE UN BAR

(4b) relaciones familiares

cuando las misiones y me llamaron a mí y tú ¿qué te pasa? ¿yo? que estoy amancebao que yo no ... entonces no estábamos casaos por la iglesia 001/64H1/PENSIONISTA DUEÑO DE UN BAR 
ya llevo quince años divorciada ya no quiero entrar en el tema 706/56M3/AMA DE CASA (DERECHO)

(4c) trabajo en casa

yo en mi pueblo tenía dos muchachas una pa que me hiciera la casa y otra pa que me cuidara al niño porque yo tenía oficina por la mañana y por la tarde 706/56M3/AMA DE CASA (DERECHO)

que ese lo he criao yo porque en mi casa siempre ha habido servicio, pero yo era la aunque esté feo decirlo era la buena de la familia era tonta como me daba mucha lástima de mi hermano pues lo he criao yo 111/55M1/AMA DE CASA

(4d) delincuencia y acciones delictivas

otra cosa que no había antes que es lo que ha traído más inseguridad y tal la droga o sea en nuestros tiempos es que no se conocía o sea nosotros no sabíamos eso que era o sea fumar esto lo otro sí pero la cuestión de de la droga y toda esa historia 711/53M3/ ADMINISTRATIVA

toos llenos de oro con tatuaje de y eran unos chusmas pero unos chusmas pero esos más dinero tenían los tíos ¿eh? 707/23H2/ESTUDIANTE

(4e) edad avanzada

los más jóvenes somos nosotros y y una familia que tiene también dos niños y ya está los demás son to personas mayores y además ya están casaos están en otra par...en otro sitio claro pero son tos personas mayores. 022/20H1/CARNICERO

entonces Antonia era la que se iba a las ocho de la mañana a lavar a las seis ancianas a asear a las seis ancianas y entonces ya era no podíamos $02855 \mathrm{H} 1$ DEPENDIENTE DE COMERCIO

(4f) defecto físico

mi padre también tuvo un accidente como el de ella, pero fue de un andamio y está inválido de una pierna y se quedó sin trabajo. 022/20H1/CARNICERO

hay desde el que está ciego que va con el bastón... hasta el que es paralitico va con los muñones arrastrándose por el suelo vamos eso eso es lo que ves una po ... una pobreza increíble vamos muy mal muy mal. 115/23M1/DEPENDIENTA

sí sí sí tú se lo dices que tiene que ir al médico bueno allí se lió una vez una con un manco que no veas el hombre porque sí era era era manco y se quería tirar de los sitios 707/23H2/ ESTUDIANTE

(4g) defecto psíquico

sí allí viven todos uno está internao porque está... vamos es deficiente y y los demás pues viven allí 114/24H1/REPRESENTANTE

eso el ma... el varón estuvo más tiempo en el colegio estuvo hasta los diecisiete años pero sin poder aprender por estar retrasao un poco. 009/80M1/AMA DE CASA 
ellos se reían de mí ya ves con dieciocho años que tenía yo y yo allí llorando como una tonta porque yo decía que no quería que me cambiaran que me había acostumbrao a aquello 023/23M1/CAJERA

o que nosotros somos muy especiales o que la gente es muy distinta pero es que te das cuenta que... sí te das cuenta que la gente está muy chala ¿eh? uno también está muy chalao pero es que la gente está un taco chala ¿eh? 026/28H2/REPRESENTANTE

(4h) raza o etnia asociada a no deseable

allí na más que había gitanos y venían de vez en cuando venían... otro colegio a pelearse venga tos ahí tos a cates ahí 022/20H1/CARNICERO

Unos chusmones pero unos chusmones con pelo de esto de lavandera ¿sabes cuál te digo? Estos que ves el estilo ¿esto así largo por detrás rizao? 707/23H2/ESTUDIANTE

hay mucha gente que que hablan de que no son racistas y tal pero bueno si si su vecino es negro ya está con la mosca detrás de la oreja ¿no? o un gitano o si su niño sale con un gitano ya está o sea que hay cosas que a niveles prácticos parece que es difícil asimilar ¿no 064/21M3/ESTUDIANTE

\subsubsection{Expresión}

Los hablantes adoptan distintas posturas a la hora de expresar eso que está prohibido expresar, bien con la estrategia de encubrir el vínculo con la realidad aludida (eufemismo), bien con la de desvelar francamente la conexión con lo referido (disfemismo), o bien con la de referirse de forma neutra o directa a la realidad tabuizada (ortofemismo) (Pizarro 2013: 81). No hay que olvidar, sin embargo, que no siempre se produce esta correspondencia y que, por ejemplo, podemos no estar haciendo referencia al concepto tabú original o primero, porque ha habido un desplazamiento de valores, y ya no tener carácter disfemístico la expresión directa. Teniendo en cuenta esto, hemos distinguido entre:

1. expresión directa (generalmente disfemismo, como recurso lingüístico que hace referencia directa a la realidad tabuizada de forma marcada)

2. expresión directa y neutra (ortofemismo, como forma lingüística que nombra directamente la realidad interdicta pero sin resultar marcado)

3. expresión indirecta (generalmente eufemismo, como recurso lingüístico que se refiere de forma indirecta a la realidad tabuizada).

Esta posibilidad de elegir una u otra forma de expresión para un mismo concepto interdicto nos da muestras de la variabilidad del fenómeno y de cómo "la selección que haga el emisor de una estrategia u otra podrá ser significativa (respondiendo, así, a requerimientos funcionales y pragmáticos) y estará condicionada por factores contextuales (la situación comunicativa) y sociales (las características sociales de los hablantes)" (Cestero 2015b: 74).

(1) expresión directa

ya suficiente tendrá el hombre con el trauma del brazo pa que se lo recuerden cuando vaya a los sitios jjoder! 707/23H2/ESTUDIANTE 
y yo no soy dispuesto yo a mí me da igual como si te lo quieres llevar a Hacienda la cinta ¡me soba la polla! que venga el que quiera aquí. 012/38H2/ADMINISTRATIVO

así está la cosa, pero es que yo tengo los cojones pa hacerlo otros no lo tienen bueno o los cojones o o la posibilidad o la fuerza 732/28H3/PROFESOR ENSEÑANZA SECUNDARIA

(2) expresión neutra

iba con mi primo y le dio un infarto de estos de miocardio pero fulminante que fue caer al suelo y y vamos muerto 727/61H2/COMERCIANTE

no quiero ni recordarla, pero vamos se me declaró el tétano tú no sabes lo que es el tétano ¿no? el tétano es... 727/61H2/COMERCIANTE

(3) expresión indirecta

nada nací yo después nació mi hermana Mari Carmen a mí me encargaron a ver septiembre octubre después de casaos 732/28H3/PROFESOR ENSEÑANZA SECUNDARIA

sí entrando y saliendo las bestias a lo mejor estábamos comiendo y estaban allí en medio la bestia y hacía su necesidad. 028 55H1 DEPENDIENTE DE COMERCIO

\subsubsection{Finalidad}

Si seguimos los últimos planteamientos pragmático-cognitivos de Casas (2012a, 2012b y 2018), debemos atender a la finalidad pragmático-discursiva con la que se hace uso de la expresión lingüística para, sobre la base del proceso cognitivo de conceptualización de lo interdicto, poder determinar si se está ante un uso lingüístico eufemístico, disfemístico o neutro. Recordamos, de nuevo, que desde este planteamiento no hay elementos lingüísticos expresamente determinados para cada una de las estrategias de expresión anteriormente consideradas, sino que, atendiendo a las interrelaciones que se establecen entre los hablantes, hablamos de usos y no de términos. Así, siguiendo de nuevo a Cestero (2015b: 86), podemos considerar las siguientes finalidades pragmático-discursivas:

1. encubrir (evitar la connotación o denotación negativas de los términos interdictos neutros y directos)

2. atenuar (evitar la amenaza a las relaciones sociales o a las imágenes del emisor o del receptor que supondría el uso de expresiones de referencia directa)

3. enfatizar (realzar el uso de la expresión que alude a la realidad interdicta)

4. informar (referirse a la realidad interdicta solo con intención informativa)

(1) encubrir

allí se juntan los niños de ocho años de diez añillos quince añillos de niños y niñas entonces allí ya se hacen de todo igual se están frotando que se están ... haciendo eso o se están fumando delante de los niños, pero chavalotes eso de quince años son iguales que de allí salen entonces entonces los niños como... los niños están viendo al otro fumar o de darse abrazos .... 028 55H1 DEPENDIENTE DE COMERCIO

claro este señor iba limpiando las las dependencias esas y entonces me pongo yo a hacer mi necesidad cuando más tranquila estoy ya que estaba yo así de buenas a primeras se abre la habitación y me aparece el fulano con la manguera 077/57M1/AMA DE CASA 
estás metiendo unas aguas fecales totalmente contaminadas y que entonces pues claro hay personas que cuando se están bañando pues se dan cuenta que efectivamente el estado del mar en cuanto a elementos de suspensión que puedan aparecer allí pues están a simple vista 714/60H3/INGENIERO INDUSTRIAL

mi padre era albañil y bueno tuvo varios oficios albañil peluquero y mi madre era sus labores 066/40H1/JEFE DE TALLER MECÁNICO

voy más bien de tarde en tarde desde que faltaron mis padres antes era rara la semana que no iba yo por allí pero ahora cuan... desde que faltaron ellos ya ... me cuesta más trabajo 077/57M1/AMA DE CASA

(2) atenuar

pa mí la hora de la comida era un poco de suplicio porque la verdad porque a pesar de eso yo estaba más bien gordita 720/64M3/MAESTRA

nada que estaba el semáforo en verde, pero un un viejecito cruzó el semáforo en verde y bueno y nosotros tuvimos que frenar derrapar allí para no darlo para no darle y bueno nos íbamos a matar allí 715/29H3/ABOGADO

la gente más estiradilla más los profesores más tontorroncillos más más puestos en su sitio más elevao y en el otro no en el otro eran muy sanotes muy bien y ya está y luego me fui a la carrera 729/22M2/ESTUDIANTE

(3) enfatizar

ya no porque se ha puesto mu gordo y él no sirve ya pa ir a correr por ahí. 108/64H1/ ALBAÑIL

no no de eso nada la gente que cree que va engañao al matrimonio son unos gilipollas 716/63H3/INGENIERO INDUSTRIAL

ahora la carta de pago la contribución yo tengo que ser el cabrón de turno que me tenga que molestar iqué se molesten ellos! 012/38H2/ADMINISTRATIVO

somos de los que protestan en el bar en la cafetería pero no tenemos cojones luego de hacer na 012/38H2/ADMINISTRATIVO

con la reforma sí tenemos mucho que exigi nos están dando mucho por culo. 00527H3PROFESOR ENSEÑANZA SECUNDARIA

(4) informar

otra cosa que no había antes que es lo que ha traído más inseguridad y tal la droga o sea en nuestros tiempos es que no se conocía o sea nosotros no sabíamos eso que era o sea fumar esto lo otro sí pero la cuestión de de la droga y toda esa historia 711/53M3/ ADMINISTRATIVA

ahora ya ellas todas han muerto y entonces voy, pero poco muy poco muy poco y me da mucha pena desde que murió mi padre volver allí al pueblo 70348M2ADMINISTRATIVA 
no aparenta la edad que tiene y porque le dio el bajón con con el infarto de miocardio 704/43M2/AMA DE CASA

\subsubsection{Función Comunicativa}

Esta variable pretende centrarse en la función que cumple el uso de determinada estrategia expresiva de la realidad tabuizada en la comunicación. Cestero (2015: 84) distingue las siguientes funciones comunicativas:

1. función referencial (uso de expresión lingüística asociada a lo interdicto para hacer referencia a lo interdicto)

2. función referencial desplazada (uso de expresión lingüística asociada a lo interdicto, pero con un significado diferente no relacionado con la interdicción)

3. función apelativa (uso de expresiones para insultar, injuriar, etc.)

4. función expresiva interjectiva (uso de formas expletivas como exclamaciones interjectivas sin valor referencial)

5. función expresiva de estilo (uso de formas expletivas como marcadores de estilo, sin valor referencial)

(1) referencial

y siempre había muchos gitanos y eso y entonces ya mi padre compró un piso aquí en Las Flores 014/35H2/PENSIONISTA

iba con mi primo y le dio un infarto de estos de miocardio pero fulminante que fue caer al suelo y y vamos muerto 727/61H2/COMERCIANTE

sí yo tengo nosotros éramos cuatro hermanos lo que pasa que uno de ellos se murió con hace ya tres años con cuarenta y yo tengo ahora cincuenta cuarenta y nueve cuarenta y cinco años por ahí murió de leucemia 719/50H3/MÉDICO

no sabía que era un embarazo y me fueron a hacer pruebas de riñón y lo que hicieron fue matarme el feto con tanta prueba de de rayos 706/56M3/AMA DE CASA (DERECHO)

(2) referencial desplazada

la mayoría se han acogido al plan de baja incentivada que es una mierda, pero bueno mejor que lo que le iban a dar. 025/27H2/TÉCNICO ELECTRÓNICO

el regalo de ese año fue la perra porque estaba loco por la perrita ... con tan mala suerte que yo regalé mi canario que estaba yo loca con mi canario 728/58M2/AMA DE CASA

(3) apelativa

¡hia puta! si llega a contar un poquillo más hasta hasta ¡no ves! ¡oh! ¡de verdad que esto e... 012/38H2/ADMINISTRATIVO

si tú le dices uno dos tres y ara cincuenta bueno y del tres al cincuenta ¿cuántos van $c a$ brón? 012/38H2/ADMINISTRATIVO 
(4) expresiva sin valor referencial

yo al final de curso bueno es que también joder es que el año pasao acabé el curso fue me tocó el peor curso del instituto, pero el peor con diferencia 732/28H3/PROFESOR ENSEÑANZA SECUNDARIA

increíble además con el frío y eso que llegabas allí te metías y ese olor y jolín me encantaba, pero es muy bonito Dublín 726/26M2/ADMINISTRATIVA

y toavía me siguen mandando a mí la carta ¡coño! pa eso no la han perdio 012/38H2/ ADMINISTRATIVO

ya ves m estaba esperando 'ya se lo había dicho a la abuela y to ¡oh Dios mío! qué mal lo pasé. 105/39M1/ AMA DE CASA

¡qué disparate! a escondias ¡no hombre! ipor Dios! 009/80M1/AMA DE CASA

sí totalmente se ha puesto ya no le considero cada vez digo hay qué ver ¿eh? es que voy paa vieja porque mi hermano chico llega con unas palabritas que digo idios! ¡esto qué es! 53/22M3/ESTUDIANTE

(5) marcadora de estilo

se declara el tío insolvente y ... como eso se lo a ... se lo acepta este puto y asqueroso gobierno como el de antes y como to los que hay que no sé a quién defienden 012/38H2/ ADMINISTRATIVO

o estoy trabajando me pueden mandar al quinto coño si me saliera una plaza aquí a lo mejor pues como espero algún día 732/28H3/PROFESOR ENSEÑANZA SECUNDARIA

pues mira era un trabajo muy tonto porque la verdad que cualquier cosa que aprendían te parecía que era... 723/74M3/MAESTRA

\section{EL ANÁLISIS}

Tratamos aquí de encontrar respuesta para las hipótesis planteadas más arriba, a partir del análisis de las 598 expresiones relativas a conceptos o realidades tabuizadas que han sido empleadas por los hablantes malagueños entrevistados para la creación del corpus PRESEEA-Málaga. Haremos también una breve comparación de nuestros resultados con los obtenidos por los estudios realizados sobre el corpus PRESEEA-Madrid y el de Granada.

\subsection{Esferas de interdicción}

En el gráfico 1 mostramos la distribución por frecuencias de las cuatro esferas tradicionalmente distinguidas con respecto al tabú. El 37,12 \% de las expresiones pertenecen a la esfera social; le siguen muy de cerca, con un $32,11 \%$, las pertenecientes a la esfera mágicoreligiosa; a la esfera sexual se refieren el 21,07 de las expresiones; y solo un 9,70\% de las 598 expresiones pertenecen a la esfera escatológica.

Parece claro que, en el discurso oral, pero con un registro medio por tratarse de conversación semidirigida, la esfera escatológica es la que se considera más interdicta por parte 
del hablante malagueño. Por otra parte, tanto en la esfera social como en la religiosa, parece tener menores reparos para el uso de expresiones referidas a ellas.

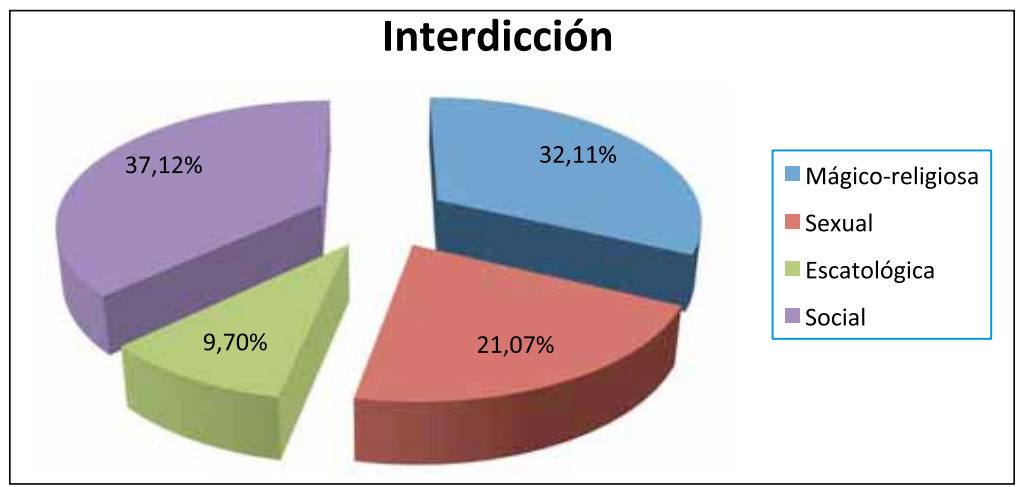

Gráfico 1. Esferas de interdicción

Si comparamos estos datos con los obtenidos en el trabajo de Cestero (2015) para el PRESEEA-Madrid y el de Jiménez (2016) para el PRESEEA-Granada, observamos la misma actitud ante la esfera escatológica, pero importantes diferencias en cuanto a la esfera social, pues, mientras tanto en Madrid como en Granada esta esfera abarca más de la mitad de las expresiones, en nuestro trabajo ocupa poco más del $37 \%$, a pesar de los múltiples apartados (edad, defectos psíquicos, físicos, delincuencia, diferencias sociales y económicas, etc.) que hemos considerado en ella. En relación con esto, nuestros datos muestran también un aumento en el empleo de expresiones referidas a las otras tres esferas. Mientras en Madrid y Granada la esfera mágico-religiosa está próxima al $20 \%$ en Málaga estamos por encima del $30 \%$. En la misma proporción aumentamos en la esfera sexual, pero solo con respecto a Granada, pues con Madrid estamos casi igualados. También doblamos en la esfera escatológica a los otros dos estudios que comparamos. Véase para esto la tabla 2 que compara los datos de frecuencia obtenidos en los tres corpus.

\begin{tabular}{|l|ccc|}
\hline \multicolumn{1}{c}{ Esfera } & MÁLAGA & GRANADA & MADRID \\
\hline Mágico-religiosa & $32,1 \%$ & $21,8 \%$ & $19,5 \%$ \\
\hline Sexual & $21,1 \%$ & $10,6 \%$ & $19,4 \%$ \\
\hline Escatológica & $9,7 \%$ & $4,0 \%$ & $4,6 \%$ \\
\hline Social & $37,1 \%$ & $63,6 \%$ & 56,6 \\
\hline
\end{tabular}

Tabla 2. Frecuencia de esferas tabú en Málaga, Granada y Madrid

\subsection{Expresión}

En cuanto a la forma de la expresión, es decir, a cómo las unidades lingüísticas seleccionadas por el hablante hacen referencia a la realidad tabú (directa, neutra, indirecta), nos encontramos que en la mayoría de las ocasiones nuestro entrevistados utilizan expresiones 
que hacen referencia a la realidad interdicta de forma directa no marcada o neutra $(54,2 \%)$. No obstante, y a pesar de tratarse de un registro medio en discurso semidirigido, encontramos un importante porcentaje de expresiones que hacen referencia a la interdicción de forma directa y disfemística (30,9\%), más del doble que el porcentaje de formas lingüísticas referidas de forma indirecta a la realidad tabú (14,9\%). Véase la proporción en el gráfico 2.

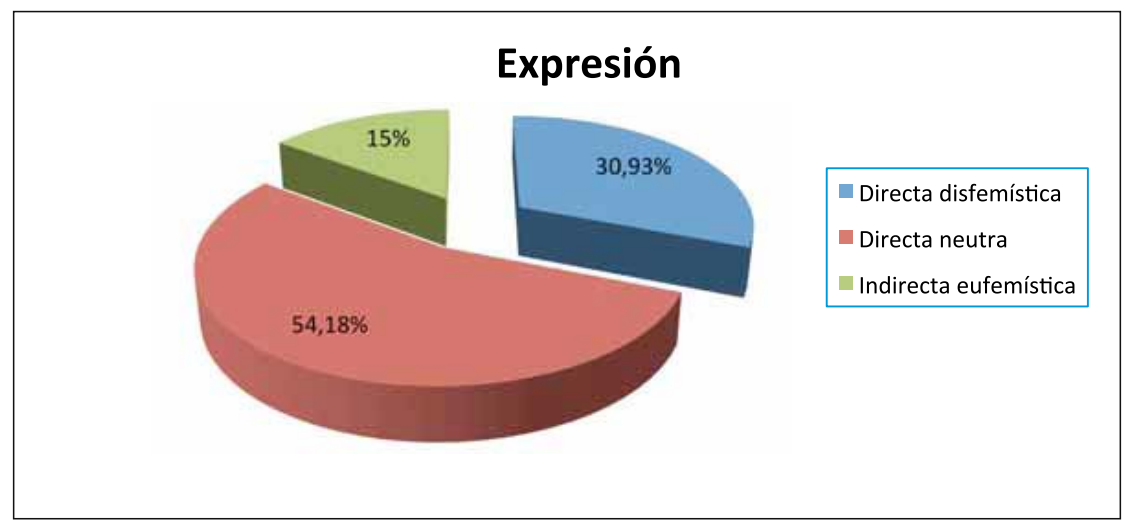

Gráfico 2. Forma de expresión del tabú

En la tabla 3 se pueden observar estos datos junto a los expuestos por los trabajos de Cestero (2015) y Jiménez (2016). Nos diferenciamos sobre todo de Madrid por nuestro mayor número de casos de expresión directa, y nos diferenciamos de Granada por nuestro mayor número de casos de expresión neutra, al igual que lo hace Madrid. En Málaga anotamos una cantidad notablemente menor en cuanto a expresiones indirectas.

\begin{tabular}{|l|c|c|c|}
\hline & Málaga & Granada & Madrid \\
\hline Directa & $30,9 \%$ & $39,4 \%$ & $11,3 \%$ \\
\hline Neutra & $54,2 \%$ & $38,6 \%$ & $61,9 \%$ \\
\hline Indirecta & $14,9 \%$ & $21,6 \%$ & $26,8 \%$ \\
\hline
\end{tabular}

Tabla 3 Expresión del tabú en Málaga, Granada y Madrid.

\subsection{Función comunicativa}

Destaca en el gráfico 3 que el 71,1 \% de los casos son referenciales (425 casos). Esto supone que el resto de las expresiones, es decir, las empleadas con función "no referencial", constituyen el 28,9\% de los casos (173), casos que, como dice Cestero (2015b: 93) "no aluden a conceptos o realidades tabú, sino que se utilizan con un contenido desplazado, como apelaciones, como expresiones interjectivas y como marcadores de estilo". Gran parte de estos casos (87 casos, 14,55\%), son "expresivas sin valor referencial" (las que Cestero llama interjectivas), otros 39 casos tienen una función de contenido desplazado $(6,5 \%)$, en 20 casos tienen la función expresiva marcadora de estilo (4\%) y solo 19 casos $(3,1 \%)$ tienen la función apelativa de insultar, injuriar, etc. 


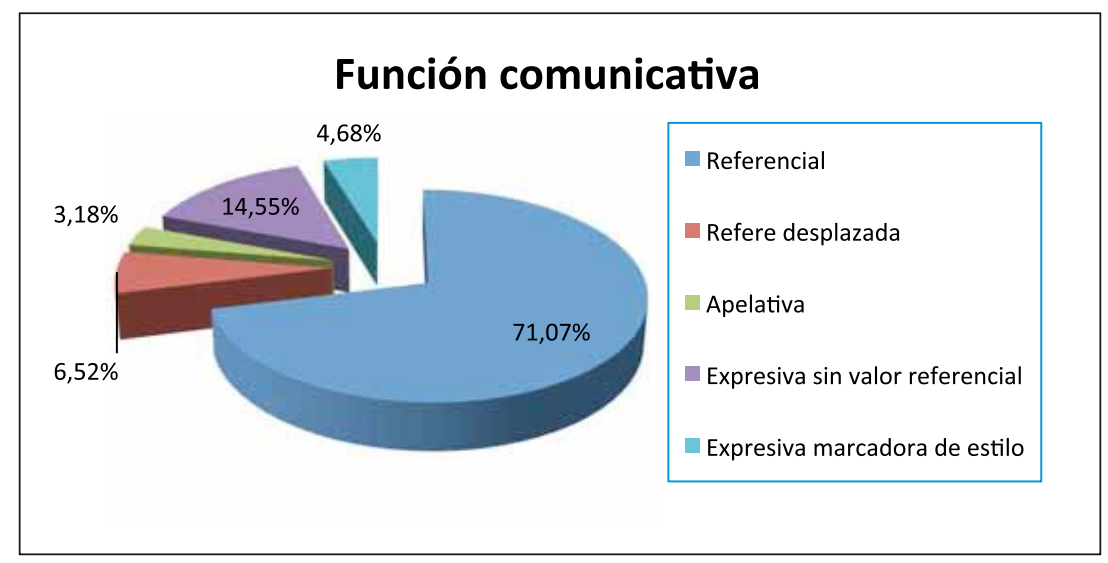

Gráfico 3. Función comunicativa en la expresión del tabú

En las tablas que siguen (4 y 5) comparamos las diferencias de nuestros datos con los encontrados en Madrid y Granada. Casi coincidimos con Granada y nos distanciamos aún más con Madrid en el porcentaje de casos con funciones no referenciales (28, 9 \% de Málaga frente al $13 \%$ de Madrid).

\begin{tabular}{|l|c|c|c|}
\hline & Málaga & Granada & Madrid \\
\hline Referencial & $71,1 \%$ & $72,1 \%$ & $87,1 \%$ \\
\hline No referencial & $28,9 \%$ & $27,8 \%$ & $13 \%$ \\
\hline
\end{tabular}

Tabla 4. Funcionalidad referencial en Málaga, Granada y Madrid

Si desglosamos los casos no referenciales y los comparamos con los datos de Granada y Madrid (tabla 5) encontramos ciertas diferencias. Además de que los dos trabajos advierten, como nosotros, de la gran proporción de estos casos con la finalidad de enfatizar, destacamos en que más de la mitad de los nuestros tienen función expresiva sin valor o interjectiva, a diferencia de Granada que sobresale en los casos con función de desplazamiento de contenido. Coincide Málaga con los otros dos grupos en la escasa representación de expresiones con función de insultar o marcadora de estilo, aunque proporcionalmente en nuestro trabajo aparece un mayor número de casos con esta función.

\begin{tabular}{|l|c|c|c|}
\hline & Málaga & Granada & Madrid \\
\hline Expresiva sin valor & $14,5 \%$ & $9 \%$ & $7 \%$ \\
\hline Desplazada & $6,5 \%$ & $13,4 \%$ & $5 \%$ \\
\hline Apelativa & $3,2 \%$ & $1,9 \%$ & $0,8 \%$ \\
\hline Marcadora de estilo & $4,7 \%$ & $2,6 \%$ & $0,1 \%$ \\
\hline
\end{tabular}

Tabla 5. Funciones no referenciales en Málaga, Granada y Madrid 


\subsection{Finalidad}

Más de la mitad de las expresiones usadas para aludir a una realidad o concepto tabú tienen la finalidad de informar $(50,8 \%, 304$ casos), gran parte de ellas con una función referencial. Véase el gráfico 4 . Le sigue la finalidad de enfatizar con un 26,4 \%, 158 casos) y la de encubrir (18,6 \%, 11 casos). Destaca el escaso porcentaje de expresiones empleadas con el fin de atenuar $(4,2 \%, 25$ casos $)$.

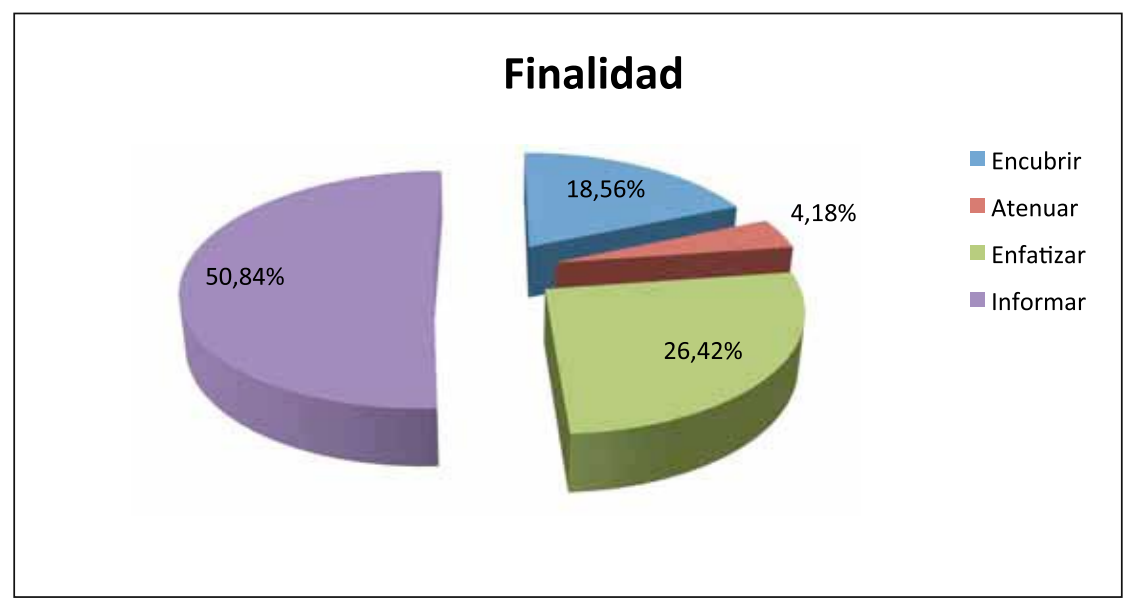

Gráfico 4. Finalidad de la expresión tabú

Cuando analizamos nuestro corpus considerando las variables sociolingüísticas distinguidas más arriba nos encontramos con algunas tendencias sociopragmáticas.

\subsection{Sexo}

En cuanto a la variable sexo, nos encontramos con que los hombres hacen mayor uso que las mujeres, casi un $15 \%$ más, de expresiones referidas a realidades o conceptos interdictos: hombres $57,4 \%$ frente a mujeres $42,6 \%$. Son datos que se oponen a los ofrecidos en el trabajo de Madrid, pues allí son las mujeres madrileñas las que tienen el $57 \%$ y los hombres el $43 \%$. Tampoco coinciden con los de Granada que ofrecen un porcentaje igualado para los dos sexos.

Con respecto al análisis de las esferas de tabú referidas por hombres y mujeres nos encontramos que la mujer malagueña solo utiliza más expresiones que los hombres en la esfera mágico-religiosa, y que el hombre la supera en las otras tres esferas, en gran medida en la esfera sexual. Véase para los datos el gráfico 5. En los datos de Granada y Madrid encontramos la misma tendencia en cuanto a la mayor proporción de expresiones de la mujer referidas a la esfera mágico-religiosa y, del mismo modo, la mayor proporción de expresiones del hombre referidas a la esfera sexual y escatológica (aunque no con una diferencia tan amplia como en el caso de los hablantes malagueños). La atención a la esfera social es diferente en nuestro análisis, pues aquí son los hombres los que hacen mayor referencia a ella, cuando tanto en Madrid como en Granada es la mujer, aunque sea escasa la diferencia en los tres casos. 


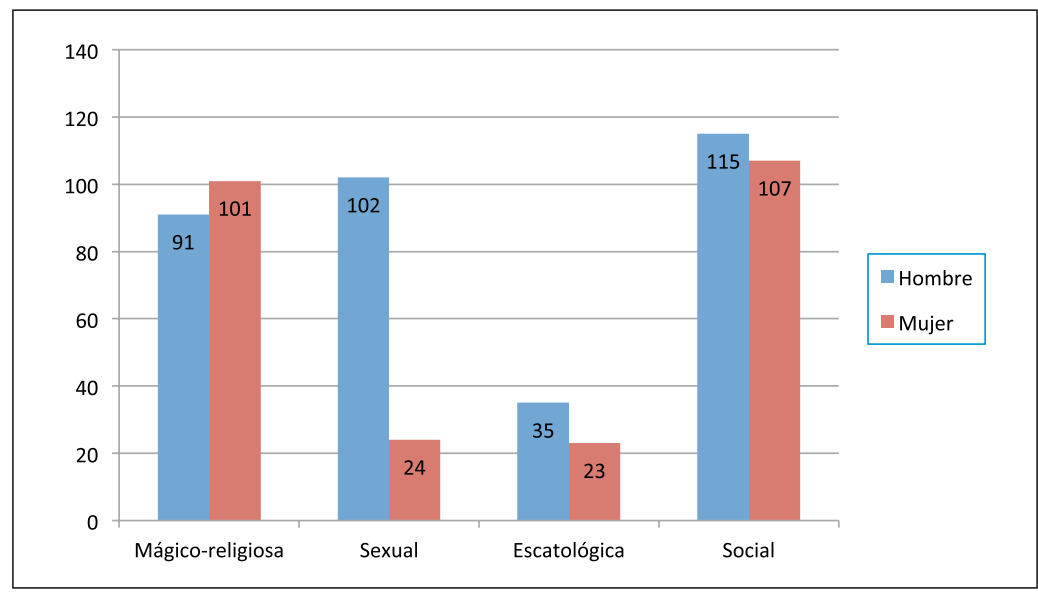

Gráfico 5. Esferas del tabú y sexo

Si pasamos a analizar qué estrategia de expresión emplean hombres y mujeres malagueños para referirse a estas esferas de interdicción, vemos en el gráfico 6 que el hombre destaca de manera notable en el uso de la estrategia directa disfemística, frente al uso que de ella hace la mujer (hombre 41,4\%, mujer 16,9), y que esta lo supera en las otras dos estrategias (mujer 65,5\% frente a hombre 45,8 en la expresión neutra, y mujer 17,6 \% frente a hombre 12,8 , en la estrategia indirecta.

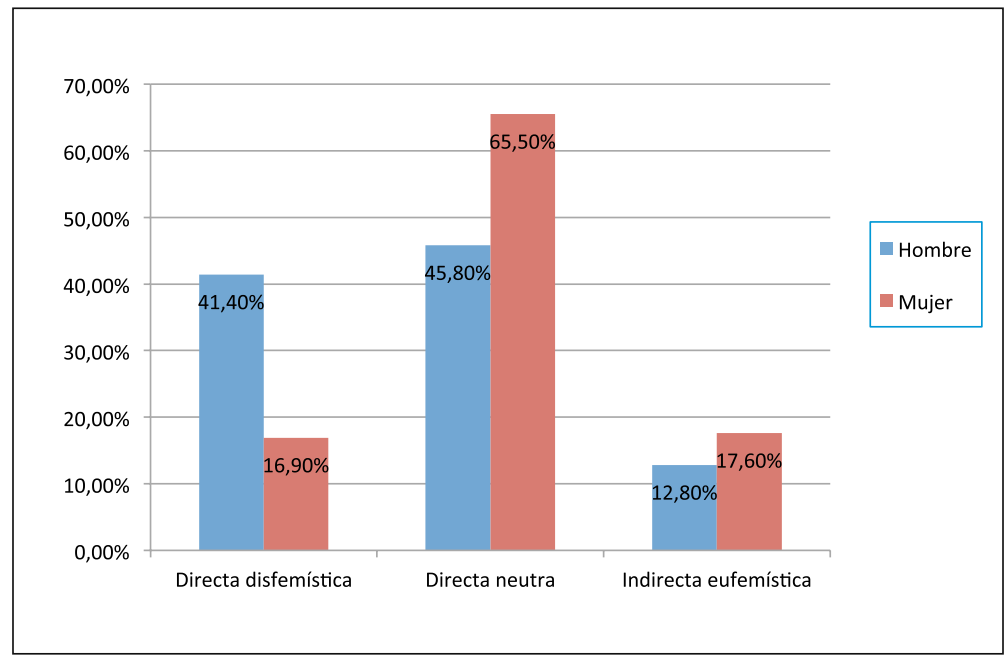

Gráfico 6 Expresión del tabú y sexo

También en los trabajos de Granada y Madrid se aprecia la tendencia de la mujer a un mayor uso de la estrategia neutra y, sobre todo, la preferencia del hombre por la estrategia directa marcada para referirse a las realidades tabúes. Los porcentajes que se reflejan en el gráfico 7 respecto a las tres comunidades muestran el mismo esquema de comportamiento. 


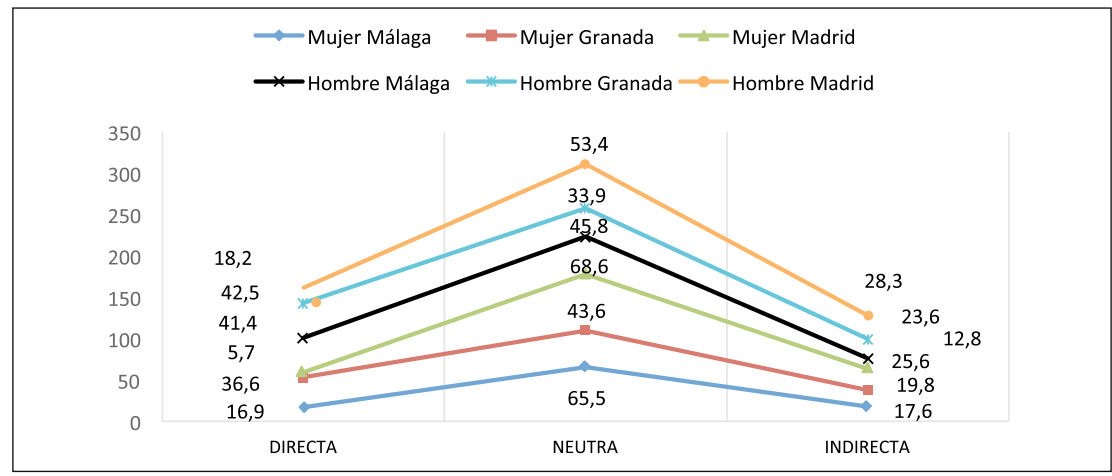

Gráfico 7. Expresión del tabú según sexo en Málaga, Granada y Madrid

En el análisis de la variable sexo hemos considerado también la finalidad con la que el hombre y la mujer de Málaga emplea la expresión de tabú. En el gráfico 8 se muestra cómo la mujer malagueña predomina en la finalidad de informar, mientras que es el malagueño el que predomina en la finalidad de enfatizar. El empleo de expresiones tabú con el fin de encubrir o de atenuar es similar en hombres y mujeres de Málaga.

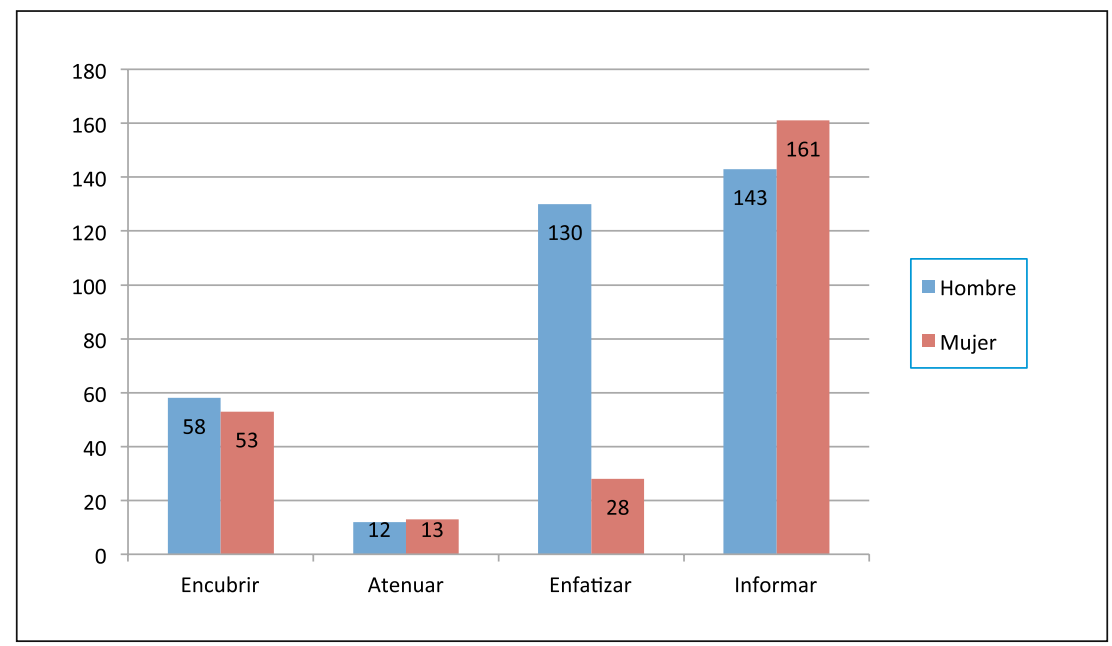

Gráfico 8. Finalidad de la expresión del tabú según sexo

El trabajo de Granada nos dice que, según sus datos, tanto hombres como mujeres tratan de encubrir, enfatizar e informar en la misma proporción, y que es solo en la finalidad de atenuar donde encuentran diferencias (más los hombres que las mujeres). De esta manera, cuando Jiménez (2016: 41) compara sus resultados con Madrid, concluye que en esta comunidad los comportamientos son diferentes a los suyos. Los resultados de nuestro trabajo en Málaga se aproximan más a los obtenidos en Madrid que a los de Granada. Como se puede ver en el gráfico 9 los porcentajes muestran que también en Madrid hay una importante 
distancia entre hombres y mujeres en cuanto a la intención de enfatizar (mayor proporción en el hombre), así como un predominio de la mujer en el uso del tabú para informar. Las finalidades de encubrir y atenuar no muestran importantes diferencias entre hombre y mujer en las dos comunidades, pero entre comunidades se observa que tanto el hombre como la mujer malagueños hacen un mayor uso de la expresión tabú con la intención de encubrir y un menor uso con la intención de atenuar que los madrileños.

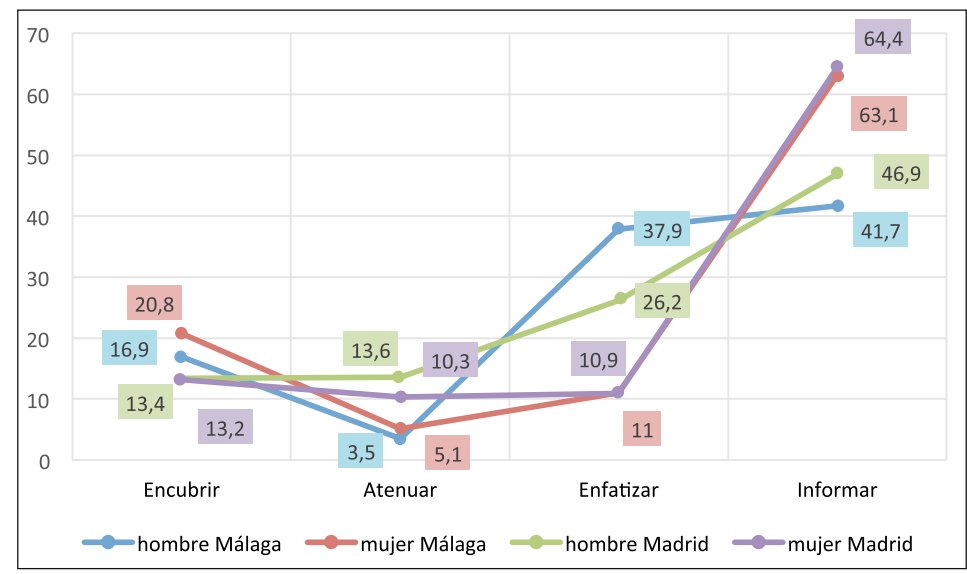

Gráfico 9. Finalidad de la expresión del tabú según sexo en Málaga y Madrid.

\subsection{Edad}

En cuanto a la variable edad de los informantes y su incidencia en la expresión del tabú hemos realizado una serie de análisis y exponemos a continuación algunos de sus resultados. Los jóvenes (menores de 34 años) con el 39,1 \% (234 casos) y los mayores (con más de 55 años) con el 39,3\% (235 casos) acumulan gran parte de las expresiones empleadas para referirse a alguna realidad tabú. La edad media adulta (35-54 años) solo presenta 129 casos (21,6 \%). En el trabajo de Madrid, sin embargo, hay mayor empleo de expresiones tabú por parte de los mayores (37\%), en menor medida de los adultos (36 \%) y menor aún en los jóvenes $(27 \%)$.

En cuanto a las esferas de tabú a las que atiende cada uno de estos grupos generacionales, observamos, en el gráfico 10, que los mayores sobresalen en gran medida en su atención a la esfera mágico-religiosa (43,8 \%, 103 casos), y que los jóvenes atienden más a la esfera social (40,6 \%, 95 casos) y, además, están proporcionalmente por encima de adultos y mayores en sus referencias escatológicas (12,8 \%, 30 casos). Los adultos superan en porcentaje a jóvenes y mayores con un $32,6 \%$ en la esfera sexual.

En el gráfico 11 mostramos la comparación de los porcentajes con el trabajo de Granada y el de Madrid y se puede apreciar que no existen grandes diferencias. También en Madrid son los jóvenes los que más emplean expresiones de tabú pertenecientes a la esfera sexual y a la escatológica, del mismo modo que son los mayores los que más acuden a la esfera mágico-religiosa. Los datos de Málaga difieren con los de Madrid únicamente en el comportamiento de los informantes adultos con respecto a la esfera social: en Madrid son estos 
adultos, y no los jóvenes como en Málaga, los que más emplean expresiones dependientes de esta esfera tabú. En cuanto a Granada, de nuevo son los mayores los que predominan con expresiones de la esfera mágico-religiosa, y los jóvenes con respecto a la esfera sexual y la escatológica. En la esfera social obtienen un porcentaje muy similar en las tres generaciones ( sin destacar alguna de ellas como ocurre en Madrid o en Málaga).

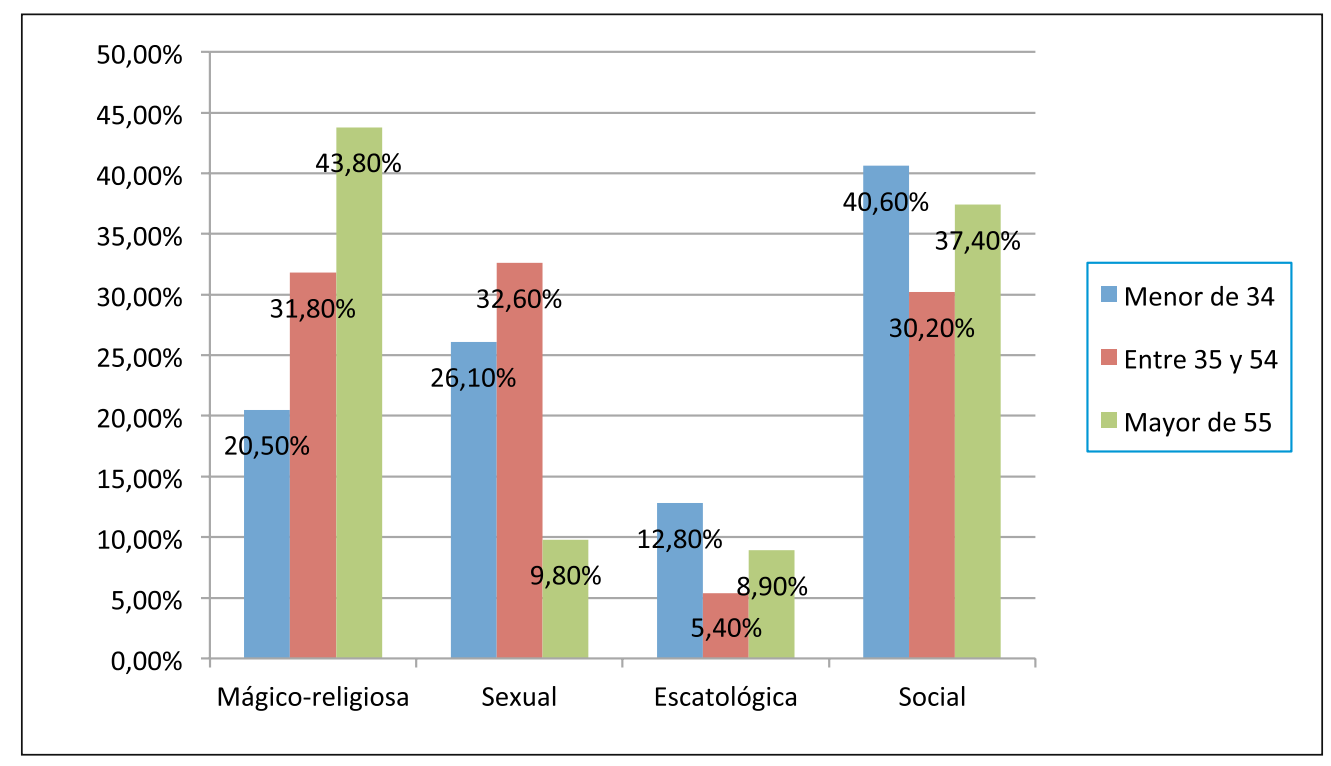

Gráfico 10 Edad y esferas tabú en Málaga

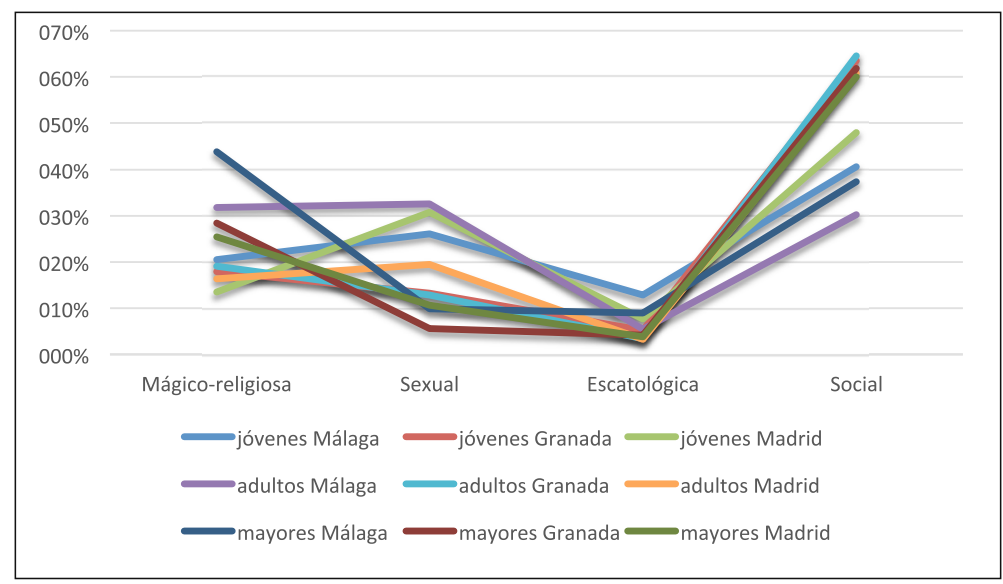

Gráfico 11. Esferas tabú y edad en Málaga, Granada y Madrid 
En cuanto a la estrategia de expresión empleada por los informantes (gráfico 12), tanto adultos como mayores hacen mayor uso de la expresión neutra (53,5 \% y 67,7 \% respectivamente) y solo los jóvenes destacan en el uso de la expresión directa o disfemística (44 \%). Los tres grupos de edad presentan un porcentaje igualado en el uso de la expresión indirecta.

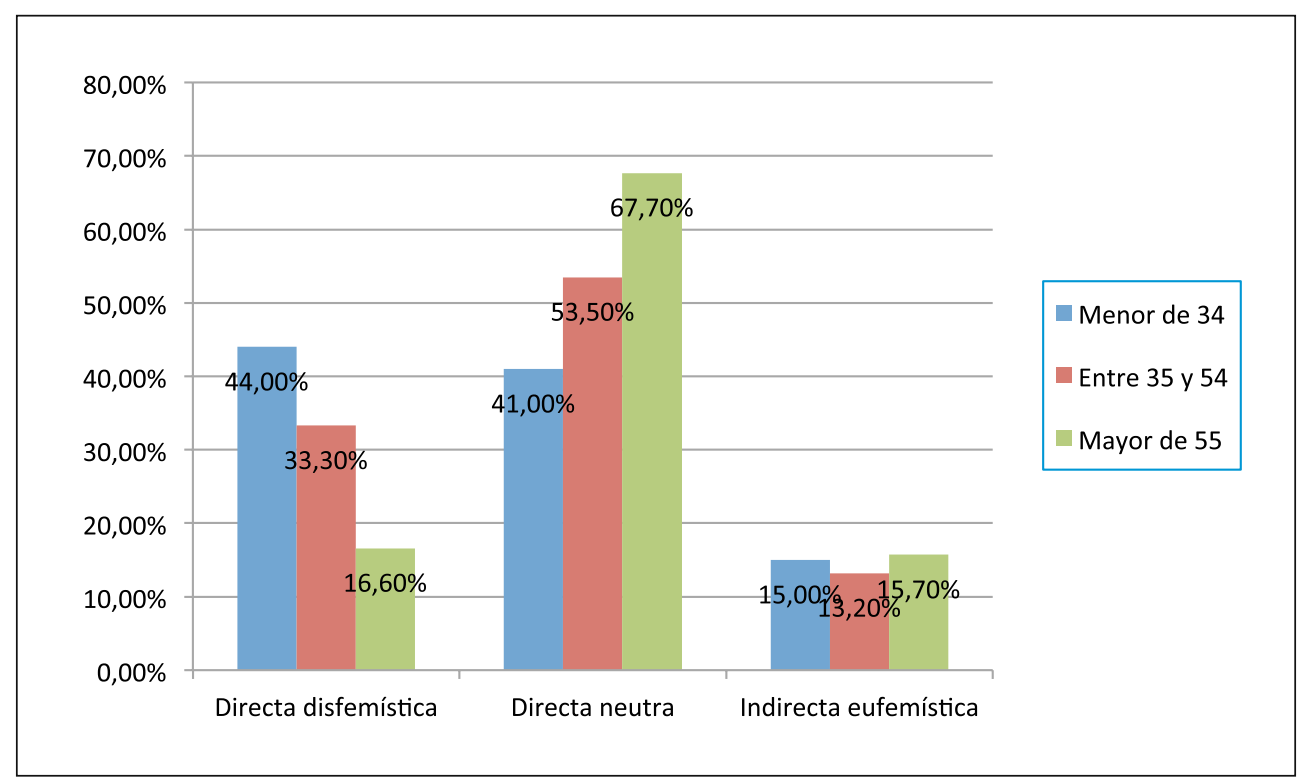

Gráfico 12 Expresión del tabú y edad

Si comparamos nuestros porcentajes con los de las otras dos comunidades, Granada y Madrid, como puede verse en el gráfico 13, en el grupo de Madrid son los adultos los que hacen un mayor empleo de la estrategia directa, mientras las tres generaciones muestran un predominio general de la estrategia neutra. También en Granada los que hacen mayor uso de la expresión directa son los adultos, mientras que son los mayores y jóvenes los que predominan en la estrategia neutra. En la estrategia indirecta muestran las tres comunidades un comportamiento equilibrado.

En cuanto a la finalidad pragmática perseguida por estos grupos de edad con el empleo de sus expresiones referidas a una realidad o concepto interdicto encontramos en nuestro análisis los siguientes datos (gráfico 14): son los malagueños mayores los que más hacen uso de las expresiones tabuizadas con la finalidad de encubrir $(21,5 \%)$, les siguen los adultos $(17,1 \%)$ y por último los jóvenes (16,2\%); es escaso en todos los grupos el empleo con la finalidad de atenuar; son los jóvenes, en correspondencia con la estrategia de expresión que más utilizaron, los que emplean en más ocasiones sus expresiones tabuizadas con el fin de enfatizar (37,2\%), siguiéndoles de cerca los mayores $(31,8 \%)$ y muy de lejos los adultos $(12,8 \%)$. La misma correspondencia se puede observar entre la estrategia de expresión neutra y la finalidad de informar: los mayores son los que ofrecen el más alto porcentaje en los dos casos, seguidos de los adultos y después de los jóvenes. 


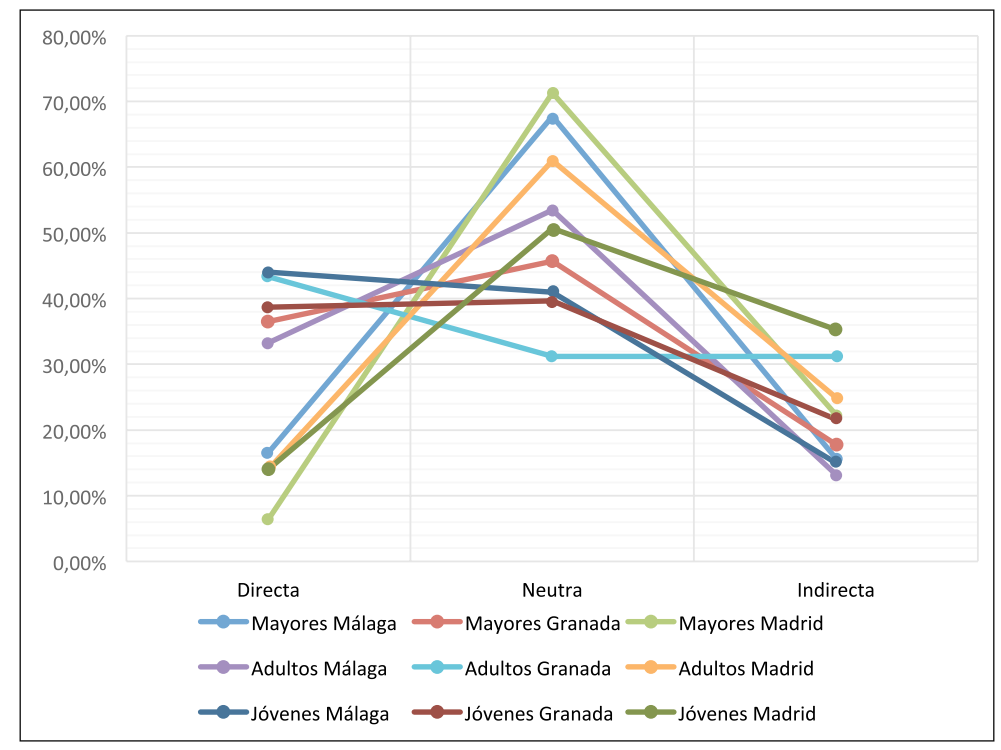

Gráfico 13. Expresión y edad en Málaga, Granada y Madrid

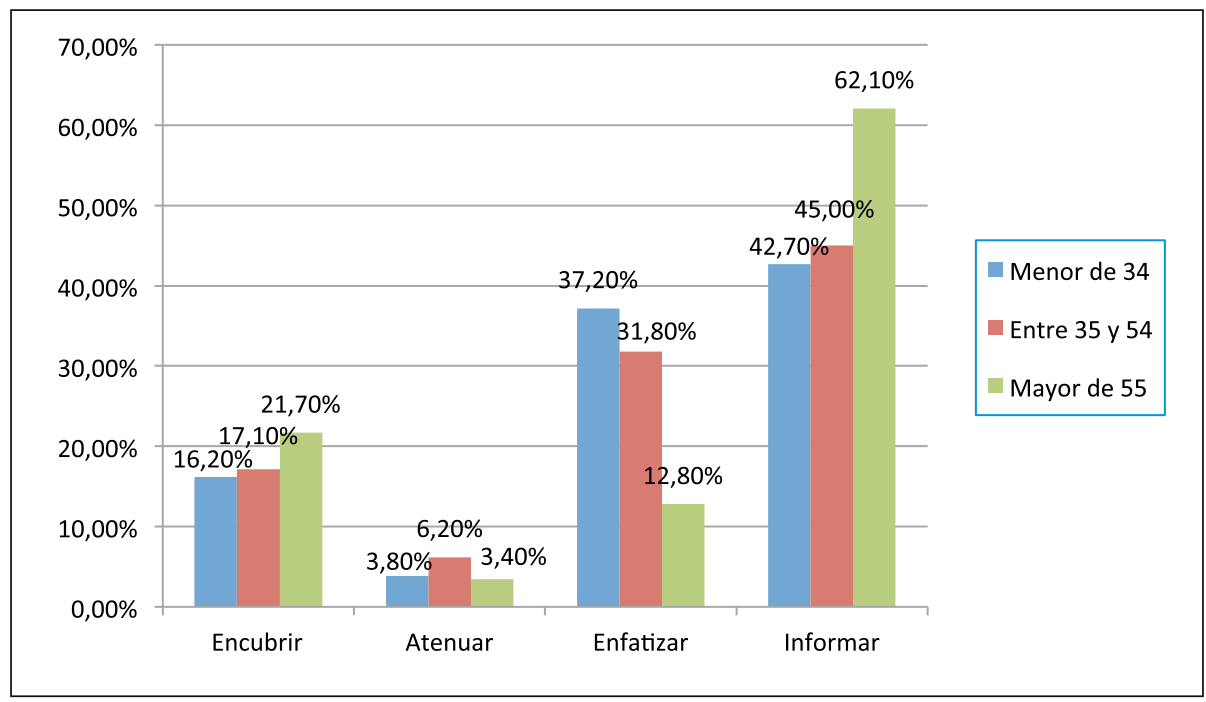

Gráfico 14. Finalidad de la expresión del tabú y edad

La comparación de los datos obtenidos en nuestros análisis con los mostrados en los trabajos de Granada y Madrid nos proporciona importantes coincidencias, aunque también algunas 
diferencias (gráfico 15). Coincidimos con Madrid en que son los hablantes jóvenes los que más utilizan las expresiones tabuizadas con el fin de enfatizar (aunque nuestro porcentaje es mucho más alto: 37,2 \% Málaga frente a 20,6 \% Madrid), mientras que en Granada son los grupos de adultos y mayores (los tres grupos muestran un porcentaje más alto: 38,6 \% mayores, $41,8 \%$ adultos y $35,1 \%$ jóvenes). No coincidimos con ninguno de los dos grupos en cuanto a la variante de informar, pues mientras en Granada destaca en su uso el grupo de los jóvenes (47,4 \%) y en Madrid el de los adultos (57,6 \%), en Málaga son los mayores los que más usan expresiones tabúes con la finalidad de informar $(62,1 \%)$. En general, son bajos en las tres comunidades los porcentajes en cuanto a la finalidad de encubrir y de atenuar $\mathrm{y}$, como puede observarse en el gráfico 15, la polarización entre encubrir y atenuar, por un lado, y enfatizar e informar, por otro, de la que habla el trabajo de Granada, falla en cuanto a enfatizar con Madrid y parece cumplirse con Málaga, a excepción del escaso empleo del fin de enfatizar por parte de los malagueños mayores.

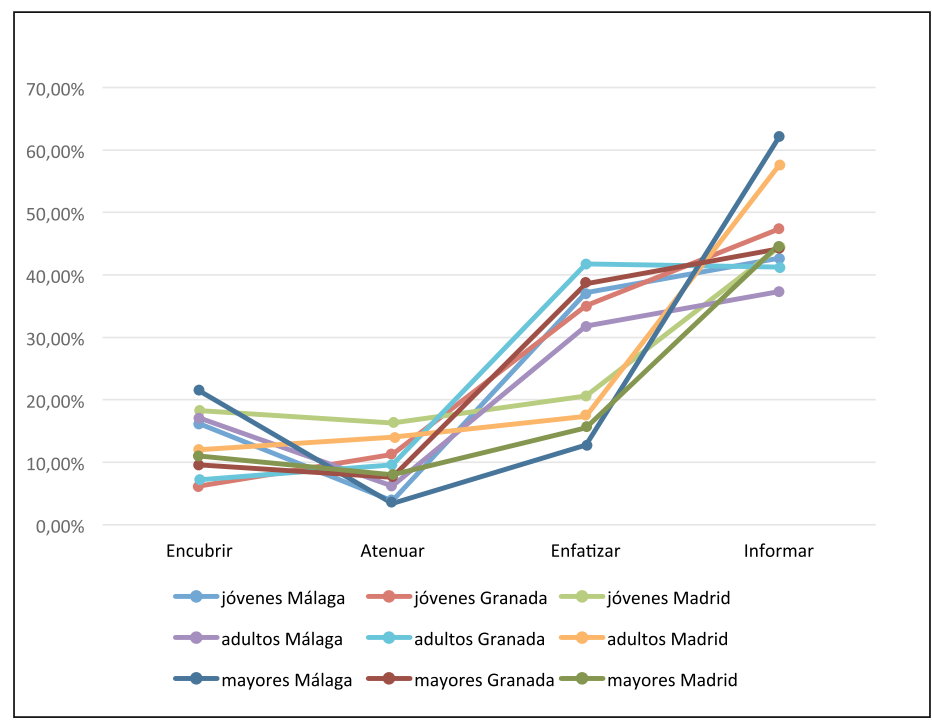

Gráfico 15 Finalidad y edad en Málaga, Granada y Madrid

\subsection{Instrucción}

Hemos considerado también en nuestros análisis el papel del nivel de instrucción de los hablantes en el empleo de expresiones referentes a realidades o conceptos tabú. En nuestros datos, son los malagueños con estudios superiores los que hacen mayor empleo de este tipo de expresiones $(39,3 \%, 235$ casos), seguidos de los hablantes con estudios secundarios $(37,1 \%, 222$ casos) y son los malagueños con estudios básicos los que acuden menos a estas expresiones $(23,6 \%, 141$ casos). Estos datos son muy distintos a los que presenta el estudio de Madrid, pues allí son los madrileños con estudios primarios los que hacen mayor empleo de expresiones que aluden a realidades tabú (Cesteros 2015b: 97). 
Si consideramos las esferas de interdicción que usan los malagueños de estos tres niveles de instrucción en su discurso oral y semiformal nos encontramos los siguientes resultados (gráfico 16): en cuanto a la esfera religiosa, son los malagueños con un nivel de instrucción medio o secundario los que acuden en más ocasiones a ella; la esfera sexual es el grupo de hablantes de nivel de instrucción superior el que más la emplea, quedando por debajo del 10 $\%$ los hablantes de nivel de instrucción bajo; son escasas en todos los niveles de instrucción las expresiones referentes a la esfera escatológica, aunque destaca algo el grupo de hablantes de nivel primario; en la esfera social son los malagueños con estudios básicos los que, en proporción, acuden a ella con mayor frecuencia.

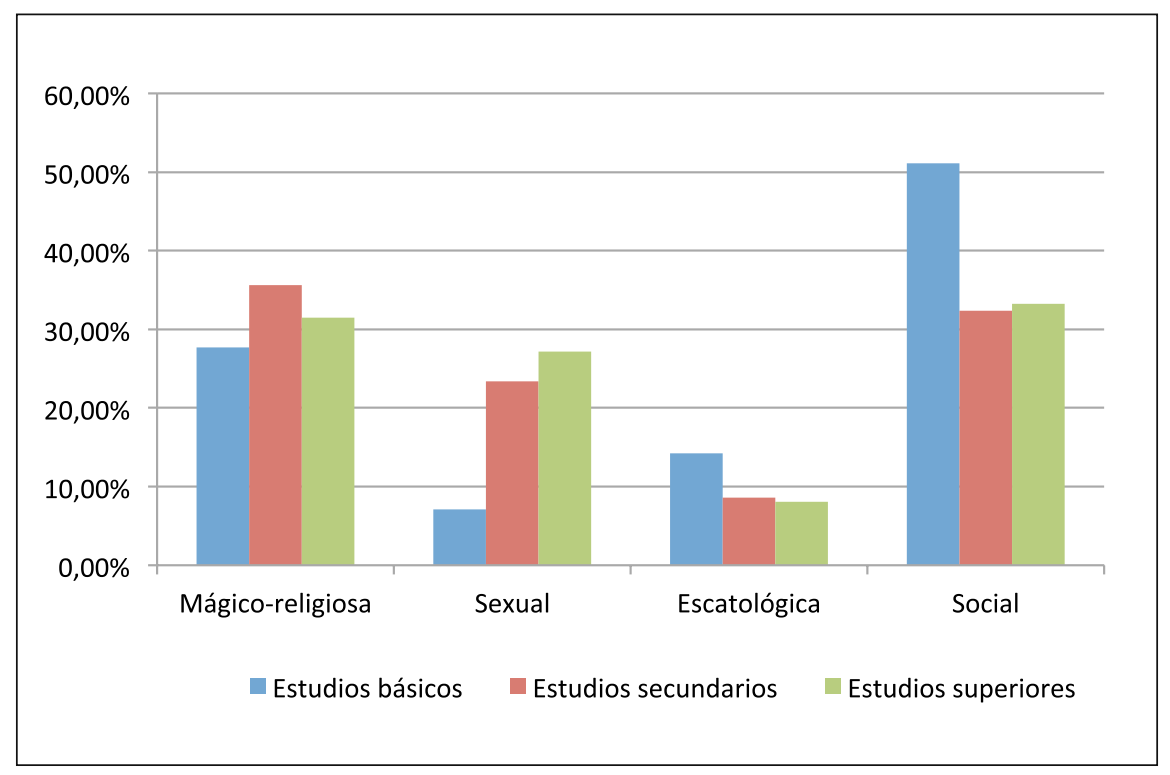

Gráfico 16. Esferas del tabú y nivel de instrucción

La comparación con el uso de estas esferas de interdicción por parte de los hablantes de las comunidades de Granada y de Madrid (gráfico 17) nos permite las siguientes observaciones: mientras que en Granada y Madrid son los hablantes de alto nivel de instrucción los que aluden en mayor porcentaje a la esfera social (72,3\% y 60,1\%, respectivamente), en Málaga son los hablantes con estudios básicos (51,1\%). Los hablantes con estudios de nivel medio de Málaga, Granada y Madrid coinciden en acudir en mayor medida a la esfera religiosa que los de los otros dos niveles de estudio considerados. La esfera sexual es más empleada por el nivel de instrucción superior en Málaga y Madrid, y por el nivel medio en Granada ${ }^{2}$. En la esfera escatológica se muestra la misma tendencia en las tres comunidades, los grupos de hablantes con nivel de estudios bajo son los que con más facilidad acuden a ella.

Hemos analizado la estrategia de expresión utilizada según el nivel de instrucción del hablante (gráfico 18). Los entrevistados con un nivel de instrucción medio, y seguidos muy

2 Como no disponemos en el trabajo de Jiménez (2016) de los datos exactos de esta esfera, empleamos las aproximaciones que deducimos de sus comentarios y del gráfico que ofrece (2016: 47). 
de cerca de los de nivel superior, son los que más uso hacen de la estrategia de expresión directa (36\% y 34,9 \%). Es el grupo de entrevistados con nivel de instrucción bajo el que más acude a la estrategia indirecta $(20,6 \%)$ y también a la estrategia neutra $(63,1 \%)$.

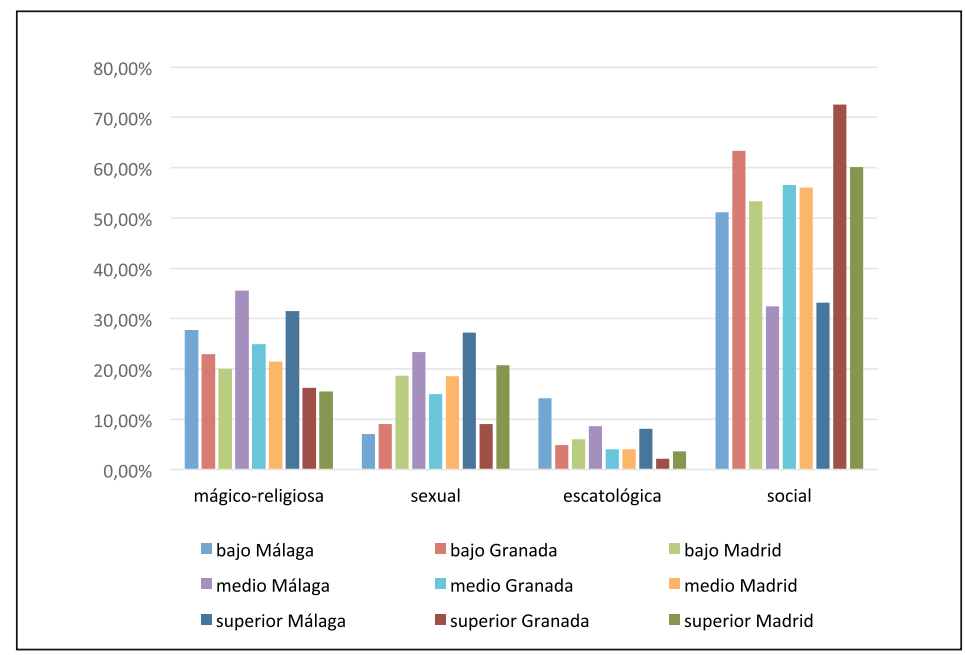

Gráfico 17. Esferas de tabú y nivel de instrucción en Málaga, Granada y Madrid

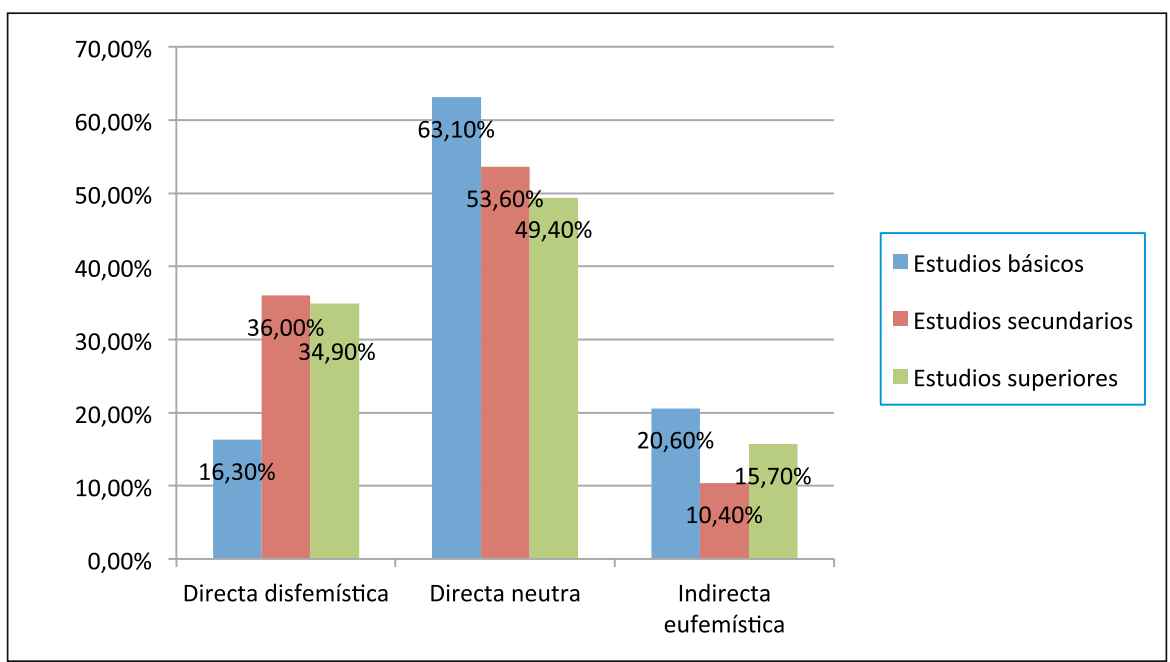

Gráfico 18. Expresión del tabú y nivel de instrucción

Si comparamos estos resultados con los datos recogidos en el trabajo de Granada y en el de Madrid (gráfico 19) observamos que, en nuestro trabajo, predomina la estrategia neutra al igual que ocurre en el estudio de Madrid, y a diferencia de Granada que muestra cierto equi- 
librio entre las tres estrategias. Nos distanciamos también, del mismo modo que ocurre en el caso de Madrid, de la comunidad de Granada en el gran empleo de la estrategia directa que tiene esta. Además, mientras Granada comprueba que a menor nivel de instrucción mayor uso de estrategia directa (Jiménez 2016: 46), en el caso de Málaga son los hablantes de nivel medio y superior los que más acuden a esta estrategia. También en Madrid se destaca este hecho de que los entrevistados con instrucción superior son los que más emplean la estrategia directa. Por último, frente a Granada y Madrid, que siguen la tendencia de que a mayor nivel de instrucción mayor empleo de la opción indirecta o eufemística, en nuestro caso, son los malagueños con estudios básicos los que predominan en el uso de esta estrategia.

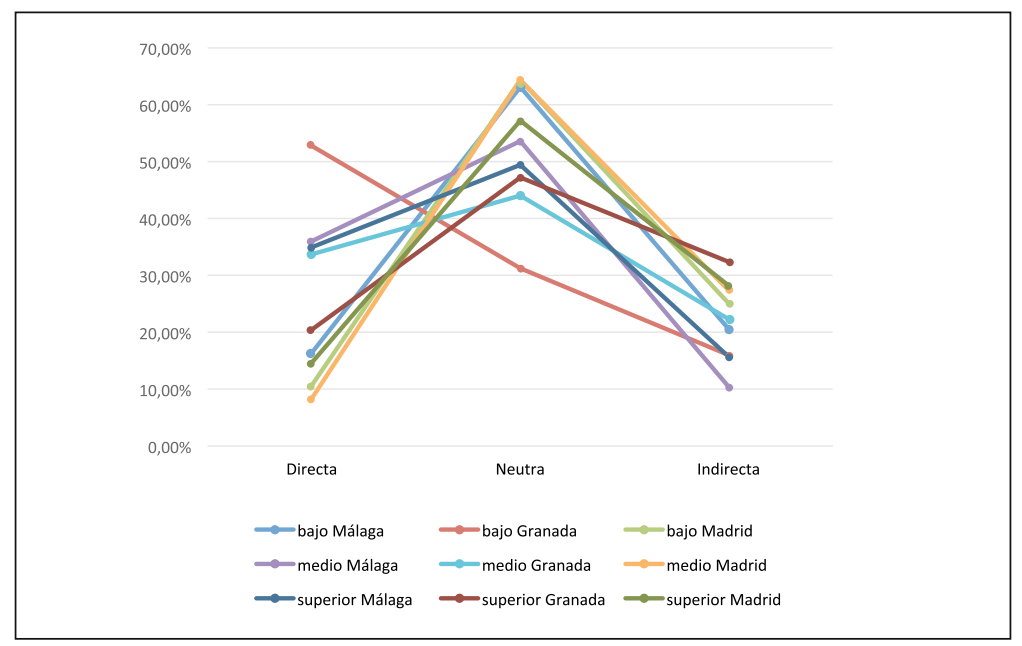

Gráfico 19. Expresión del tabú y nivel de instrucción en Málaga, Granada y Madrid

Hemos analizado la finalidad con la que se utilizan las expresiones referidas a una realidad o concepto tabú según el nivel de instrucción de los hablantes (gráfico 20). Los malagueños con un nivel básico de instrucción son los que más utilizan estas expresiones con el fin de informar $(58,2 \%)$ y también destacan sobre los otros dos niveles en la finalidad encubridora $(24,1 \%)$. Es el nivel de instrucción medio, seguido de cerca del nivel superior, el que destaca sobre el resto en el empleo de esas expresiones tabú con el fin de enfatizar $(34,2 \%$ y $28,5 \%$ ). Los tres niveles de instrucción muestran un bajo empleo de las expresiones con la finalidad atenuadora, así como un alto empleo con la finalidad informativa.

La comparación de estos resultados con los obtenidos en los trabajos de Granada y Madrid arroja las siguientes observaciones (gráfico 21): la diferencia principal con el hablante granadino de baja instrucción está en el alto empleo de la finalidad de enfatizar (44 $\%$ aproximadamente ${ }^{3}$, frente al $10,6 \%$ de Málaga), mientras que el malagueño del mismo nivel de instrucción destaca en el uso de la finalidad encubridora $(24,1 \%)$. Con respecto a la comunidad de Granada, también destaca el hecho de que en esta son los informantes de instrucción superior los que más expresan el tabú con finalidad informativa, mientras que

3 Deducimos estos datos de forma aproximada a partir de nuestra observación del gráfico que muestra el trabajo de Jiménez (2016: 50), ya que este no aporta la etiqueta del porcentaje exacto. 
en Málaga y en Madrid son los de nivel de instrucción básico (58,2 \% y 62 \% respectivamente). En la comunidad de Madrid los tres niveles de instrucción están con un porcentaje por encima del resto en la finalidad de informar y baja mucho el porcentaje con Málaga y Granada en la de enfatizar (excepto con Málaga en el nivel de instrucción bajo).

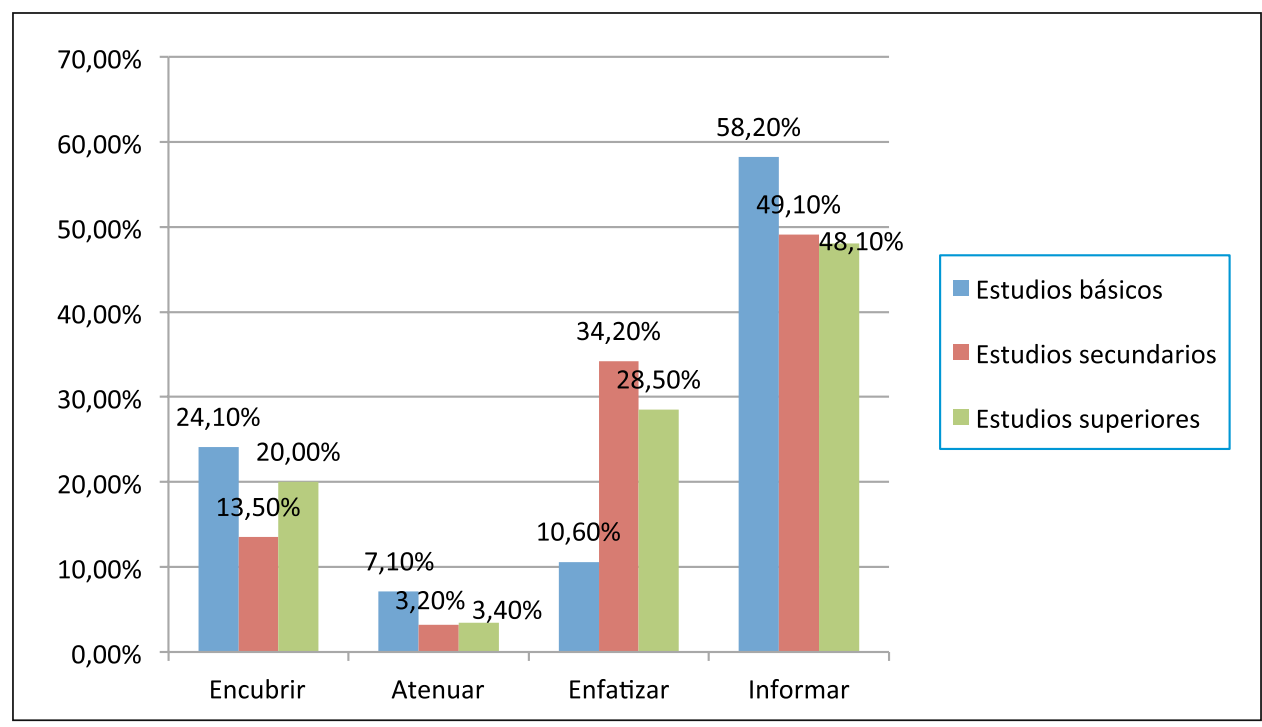

Gráfico 20. Finalidad del tabú y nivel de instrucción

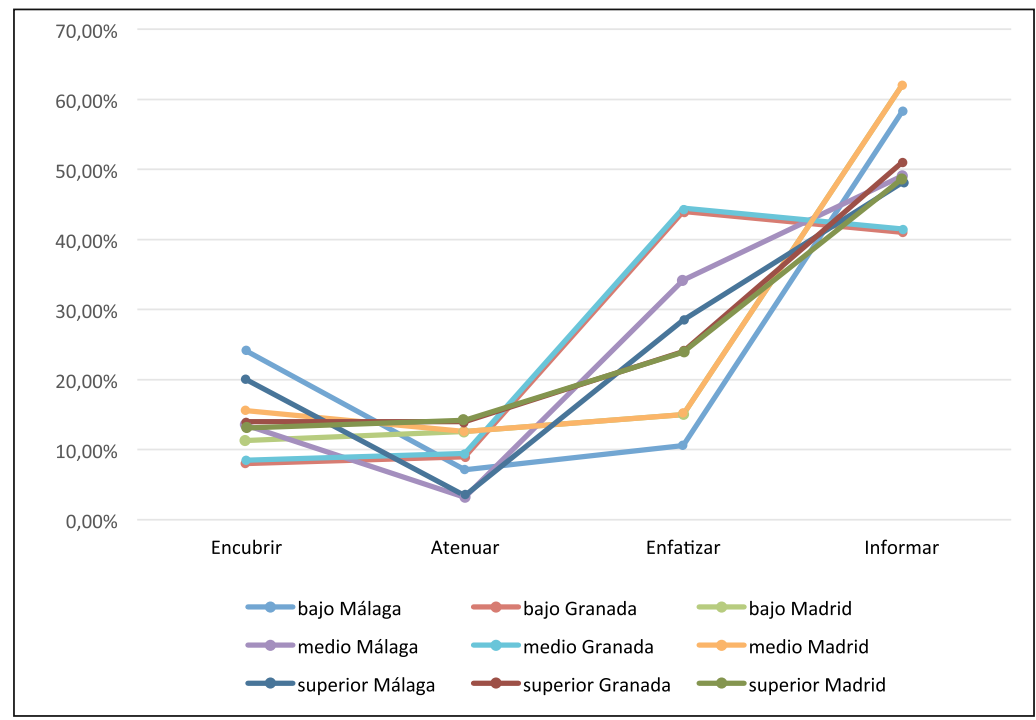

Gráfico 21. Finalidad del tabú y nivel de instrucción en Málaga, Granada y Madrid 


\section{CONCLUSIONES}

Los avances en las investigaciones sobre la interdicción y su expresión han llevado a la determinación de que solo es posible un profundo acercamiento a este fenómeno mediante un análisis simultáneo desde diferentes ámbitos lingüísticos y extralingüísticos.

En esta línea se encuentra la aportación de nuestro trabajo de tomar en consideración la expresión de las realidades y conceptos interdictos en el discurso oral (aunque sea en un registro medio formal) por parte de los hablantes malagueños y analizarlas atendiendo a determinadas variables pragmático-discursivas (expresión, finalidad, función) así como a las características sociolingüísticas (sexo, edad, instrucción) de estos hablantes.

Aunque aquí no hemos podido dar muestras de todos los análisis realizados, sí que hemos podido dar respuesta a la mayor parte de los objetivos que exponíamos más arriba. Mencionaremos a continuación algunas de las conclusiones a las que hemos llegado con nuestros análisis.

De las cuatro esferas de interdicción consideradas, el hablante malagueño parece considerar más interdicta la esfera escatológica, pues es a la que alude en menos ocasiones con sus expresiones.

Aunque en más de la mitad de los casos analizados los hablantes han seguido una estrategia de expresión neutra (directa no marcada), hay un importante porcentaje de referencias a la interdicción de forma directa o disfemística $(30,9 \%)$ y en menor medida de forma indirecta o eufemística $(14,9 \%)$.

Más del $70 \%$ de los casos han tenido una función comunicativa referencial y entre los casos empleados con función "no referencial" ha destacado el empleo de la función expresiva sin valor referencial o interjectiva (casi un 15\%).

La finalidad perseguida por los hablantes con el empleo de sus expresiones ha sido en más de la mitad de los casos la de informar, aunque también han querido en muchos casos $(26,4 \%)$ enfatizar y, en menor medida, encubrir y atenuar.

Los hombres malagueños hacen mayor uso que las mujeres, casi un $15 \%$ más, de expresiones que aluden a realidades o conceptos interdictos, especialmente en las referidas a la esfera sexual. La mujer malagueña solo utiliza más expresiones que los hombres en la esfera mágico-religiosa. Mientras el hablante malagueño destaca por el uso de la estrategia directa o disfemística, la mujer malagueña lo supera en la expresión neutra y en la indirecta. Y en cuanto a la finalidad que persiguen en cada caso, la mujer malagueña predomina en la finalidad de informar, mientras que es el malagueño el que predomina en la finalidad de enfatizar.

Son los jóvenes y los mayores malagueños los que emplean gran parte de los casos analizados; los mayores atendiendo a la esfera religiosa y los jóvenes a la esfera social. Los adultos superan a jóvenes y mayores en su atención a la esfera sexual y, sin embargo, son los jóvenes los que destacan en el uso de la estrategia de expresión directa o disfemística. Los tres grupos de edad muestran un porcentaje parecido en el uso de la expresión indirecta. En cuanto a la finalidad pragmática perseguida es escaso en los tres grupos de edad el fin de atenuar y destaca que los jóvenes son los que más tienen la intención de enfatizar, mostrando cierta correspondencia con el predominio de estos jóvenes en la estrategia de expresión directa o disfemística. El mismo patrón se observa en cuanto a la finalidad de informar y la estrategia de expresión neutra: son los mayores malagueños los que ofrecen el más alto porcentaje en las dos ocasiones. 
Los malagueños con estudios superiores son los que hacen mayor empleo de expresiones referentes a realidades o conceptos tabú (casi un $40 \%$ ), seguidos de los malagueños con estudios medios (37\%). Estos últimos son los que más acuden a la esfera religiosa y los primeros, los malagueños de nivel de instrucción superior, son los que más acuden a la sexual. Los malagueños con estudios básicos sobresalen en casos referentes a la esfera social.

La comparación de nuestros resultados con los obtenidos por los trabajos de Granada (2016) y Cestero (2015) ha servido para advertir muchas semejanzas de actuación de los hablantes en los tres territorios, y también algunas diferencias. Destacamos, a continuación, algunas.

Más de la mitad del tipo de expresiones que nos ocupan empleadas por madrileños y granadinos se refieren a la esfera social y procuran no acudir a la esfera escatológica. Los malagueños, aunque muestran la misma tendencia, no acuden tanto a la esfera social ni tan poco a la escatológica. Coincide Málaga y Madrid, frente a Granada, en el mayor empleo de expresiones referentes a la esfera sexual.

Los malagueños nos diferenciamos de los madrileños por nuestro mayor número de casos de expresión directa. Tanto malagueños como madrileños acudimos mucho más que los granadinos a la estrategia de expresión neutra. El hablante malagueño presenta menor cantidad de casos de expresiones indirectas.

En las tres comunidades hay un predominio de la función referencial de los casos analizados y, además, se advierte que gran parte de los casos con funciones no referenciales tienen la finalidad de enfatizar.

Nos diferenciamos del estudio de Madrid en cuanto a la variable sexo, pues en él son las mujeres, y no los hombres como en el de Málaga, las que hacen mayor uso de expresiones referidas a realidades o conceptos interdictos.

Tanto Granada, como Málaga y Madrid, muestran una mayor proporción de expresiones de la mujer referidas a la esfera mágico-religiosa y, del mismo modo, la mayor proporción de expresiones del hombre referidas a la esfera sexual y escatológica.

También en las tres comunidades se aprecia la tendencia de la mujer a un mayor uso de la estrategia de expresión neutra $\mathrm{y}$, sobre todo, la preferencia del hombre por la estrategia directa marcada.

En cuanto a la finalidad en el empleo de los casos analizados observamos un comportamiento semejante en Málaga y Madrid: los hombres con mayor empleo con la intención de enfatizar y las mujeres con mayor empleo con el fin de informar. Sin embargo, el hablante granadino, hombre o mujer, muestra empleo equilibrado con las intenciones de enfatizar, encubrir y atenuar.

Con respeto a la variable edad son los jóvenes de las tres comunidades los que más emplean casos pertenecientes a la esfera sexual y a la escatológica, del mismo modo que son los mayores los que más acuden a la esfera mágico-religiosa. Mientras que a la esfera social acuden en Málaga los jóvenes, en Madrid lo hacen los adultos.

En cuanto a la estrategia de expresión empleada en relación con la edad, las tres comunidades solo coinciden en la estrategia indirecta. Mientras en Málaga son los jóvenes los que destacan en el uso de la expresión directa o disfemística, en Granada y Madrid son los adultos. Mientras en Granada predominan los mayores y los jóvenes en la estrategia de expresión neutra, en Madrid el predominio es general en los tres grupos de edad, y en Málaga son los adultos y mayores. 
Mientras que en Málaga y Madrid son los hablantes jóvenes los que más utilizan casos con el fin de enfatizar, en Granada son los grupos de adultos y mayores. Tampoco coincidimos en cuanto a la variante de informar, pues en Granada destaca su uso en el grupo de los jóvenes, en Madrid en el de los adultos y en Málaga en el de los mayores. Granada habla de una polarización entre encubrir y atenuar, por un lado, y enfatizar e informar, por otro, que no se produce, en el caso de enfatizar, con ningún grupo de edad de Madrid y tampoco con el de mayores de Málaga.

La esfera social es más atendida en Granada y Madrid por hablantes de alto nivel de instrucción, mientras que en Málaga lo es por hablantes con estudios básicos. Coinciden las tres comunidades en que los hablantes con estudios de nivel medio acuden en mayor medida a la esfera religiosa y los de nivel de estudios bajo a la esfera escatológica.

Mientras que en Granada son los hablantes con menor nivel de instrucción los que mayor uso de la estrategia de expresión directa, tanto en Málaga como en Madrid lo hacen los hablantes con un nivel alto de instrucción. Al contrario que las otras dos comunidades, en Málaga son los hablantes con estudios básicos los que más acuden a la estrategia de expresión indirecta.

La finalidad de enfatizar predomina en el hablante granadino de baja instrucción y la finalidad de informar en el de instrucción superior. En Málaga y Madrid no ocurre así y, además, son los hablantes con un nivel de instrucción básico los que predominan en la finalidad informativa.

\section{REFERENCIAS BIBLIOGRÁFICAS}

Alonso Moya, M. (1988). El eufemismo en inglés. Madrid: Universidad Complutense (tesis doctoral). Ávila Muñoz, A., Lasarte Cervantes, M ${ }^{\mathrm{a}}$ C. y Villena Ponsoda, J. A. (eds.) (2008). El español hablado en Málaga II. Málaga: Sarriá.

Calvo Shadid, A. (2009). Análisis sociolingüistico sobre el tabú sexual en el español de Costa Rica. Tesis doctoral para optar por el grado de Dr. Universidad de Bergen, Noruega.

Calvo Shadid, A. (2011). "Sobre el tabú, el tabú lingüístico y su estado de la cuestión", Kañina, Revista Artes y Letras, Universidad de Costa Rica XXXV (2), pp. 121-145. Disponible en http:// revistas.ucr.ac.cr/index.php/kanina/article/viewFile/558/617.

Casas Gómez, M. (1995). "Sinonimia y eufemismo", Quaderni di Semantica, 16,1, pp. 17-46.

Casas Gómez, M. (2000). "Tabú de palabra e interdicción conceptual”. En Pamies, A. y J. de D. Luque (eds.). Trabajos de lexicografía y fraseología contrastiva. Granada: Método Ediciones, pp. 79-98.

Casas Gómez, M. (2005). "Precisiones conceptuales en el ámbito de la interdicción lingüística". En Santos, L. et al. (eds.). Palabras, norma, discurso. En memoria de Fernando Lázaro Carreter. Salamanca: Ediciones Universidad de Salamanca. pp. 271-290.

Casas Gómez, M. (2012a). "De una visión léxica y pragmático-discursiva a una dimensión cognitiva en la caracterización extralingüística y lingüística del eufemismo". En Bonhomme, M., de la Torre, M. y A. Horak (eds.). Estudios pragmático-discursivos sobre el eufemismo. Frankfurt am Main: Peter Lang, pp. 53-72.

Casas Gómez, M. (2012b). “El realce expresivo como función eufemística: a propósito de la corrección política de ciertos usos lingüísticos". En Reutner, U. y E. Schafroth. (eds.). Political Correctness. Frankfurt am Main: Peter Lang, pp. 61-77.

Casas Gómez, M. (2018). "Lexicon, Discourse and Cognition: Terminological Delimitations in the Conceptualizations of Linguistic Taboo". En Pizarro Pedraza, A. (ed.), Linguistic Taboo Revisited. Novel Insights from Cognitive Perspectives. Berlin: Mouton De Gruyter, Cognitive Linguistics Research, vol. 61, pp. 13-31. 
Cestero Mancera, A. Ma (2015a). "El estudio sociolingüístico de Madrid". En Cestero Mancera, A. M., Molina Martos, I. y F. Paredes García (eds.). Patrones sociolingüísticos de Madrid. Frankfurt am Main: Peter Lang, pp. 17-62.

Cestero Mancera, A. Ma (2015b): "La expresión del tabú: estudio sociolingüístico", Boletín de Filología, 1, Chile, Universidad de Chile, pp. 71-105.

Chamizo Domínguez, P.J. \& Sánchez Benedito, F. (2000). Lo que nunca se aprendió en clase. Eufemismos y disfemismos en el lenguaje erótico inglés. Alicante: Universidad de Alicante.

Coseriu. E. (1991). "La creación metafórica en el lenguaje", en El hombre y su lenguaje, Madrid: Gredos, pp. 66-102.

Crespo Fernández, E. (2007). El eufemismo y el disfemismo. Procesos de manipulación del tabú en el lenguaje literario inglés. Alicante: Universidad de Alicante.

Ducrot, O. (1982). Decir y no decir. Principios de semántica lingüística. Barcelona: Anagrama.

Guerrero Salazar, S. (2007. "El eufemismo desde la perspectiva de género", en Durán, $\mathrm{M}^{\mathrm{a}}$ Á. (coord.). Mujeres, simbolismo y vida. Málaga: Universidad de Málaga, pp. 51-67.

Guerrero Salazar, S. (2012). "Los eufemismos en los anuncios de contacto en lengua española". En Bonhomme, M., de la Torre, M. y A. Horak (eds.). Estudios pragmático-discursivos sobre el eufemismo. Peter Lang, pp. 119-132.

Horak, A. (2012). "Les recherches sur l'euphémisme des origines à nos jours". En Bonhomme, M., de la Torre, M. y A. Horak (eds.). Estudios pragmático-discursivos sobre el eufemismo. Peter Lang, pp. 37-51.

Jiménez Morales, B. (2016). "El tabú en el habla de Granada: análisis sociolingüístico", Normas 6, pp. 29-52.

Lasarte, Cervantes, Mª C., Sánchez Sáez, J. M., Ávila Muñoz, A. y Villena Ponsoda, J. A. (eds.) (2008). El español hablado en Málaga III. Málaga: Sarriá.

López Morales, H. (1990). Sociolingüística del tabú. El caso de Puerto Rico. Madrid: MS.

López Morales, H. (1997). "Papel del nivel sociocultural y del estilo lingüístico en el uso del eufemismo". En Moreno Fernández, F. (ed.), Trabajos de sociolingüística hispánica. Alcalá de Henares: Servicio de Publicaciones de la UAH, pp. 27-33.

López Morales, H. (2001). "Estratificación social del tabú lingüístico: el caso de Puerto Rico”, Estudios de lingüistica del español, 13. Publicado en: http://elies.rediris.es/elies13/index.htm\#indice.

López Morales, H. (2005). "Sociolingüística del tabú", Interlingüística, 16 (1), pp. 7-20. Publicado en: https://ialnet.unirioja.es/servlet/articulo?codigo=2514205.

Martín Fernández, $M^{a}$ I. (1994). "Sobre la utilidad de la pragmática en la clasificación de los eufemismos", Anuario de Estudios Filológicos, XVII, pp. 325-338.

Martínez Valdueza, Mª. P. (1995). El tabú lingüístico: estudio sociolingüístico de Las Palmas de Gran Canaria. Tesis para optar al grado de Doctora, Universidad de Las Palmas de Gran Canaria.

Montero, E. (1981). El eufemismo en Galicia (su comparación con otras áreas romances). Santiago de Compostela: Universidad de Santiago de Compostela.

Moreno Fernández, F. (2003). Metodología del "Proyecto para el estudio sociolingüístico del español de España y América" (PRESEEA), oct. 2003. Publicado en: http://preseea.linguas.net/ Metodolog\%C3\%ADa.aspx.

Pizarro Pedraza, A. (2013). Tabú y eufemismo en la ciudad de Madrid. Estudio sociolingüísticocognitivo de los conceptos sexuales. Tesis para optar al grado de Doctora, Universidad Complutense de Madrid. Disponible en http://eprints.ucm.es/24937/1/T35255.pdf.

Ullmann, S. (1976). Semántica. Introducción a la ciencia del significado. Madrid: Aguilar.

Uría Varela, J. (1997). Tabú y eufemismo en latín. Amsterdam: A. M. Hakkert-Publisher.

Vida Castro, M. (ed.) (2007). El español hablado en Málaga. Málaga: Sarriá. 